\title{
Damage Identification for Prestressed Adjacent Box-Beam Bridges
}

\author{
Kenneth K. Walsh, ${ }^{1}$ Brendan T. Kelly, ${ }^{2}$ and Eric P. Steinberg ${ }^{1}$ \\ ${ }^{1}$ Department of Civil Engineering, Ohio University, Athens, OH 45701, USA \\ ${ }^{2}$ GPD Group, 1801 Watermark Drive, Suite 150, Columbus, OH 43215, USA \\ Correspondence should be addressed to Kenneth K. Walsh; walshk@ohio.edu
}

Received 31 May 2014; Accepted 25 August 2014; Published 23 September 2014

Academic Editor: Andreas Kappos

Copyright (c) 2014 Kenneth K. Walsh et al. This is an open access article distributed under the Creative Commons Attribution License, which permits unrestricted use, distribution, and reproduction in any medium, provided the original work is properly cited.

\begin{abstract}
Structural health monitoring (SHM) has gained considerable attention as a tool for monitoring the health of civil infrastructure. For bridge infrastructure, previous methods have focused on the detection of localized damage through modal parameters extracted from the longitudinal direction of the structure. This paper investigates a new damage detection method based on the change in the first vertical mode extracted from the transverse direction of the bridge. The mode is determined through application of modal curve fitting to frequency response functions (FRFs) that are formed using vertical response data obtained in the direction perpendicular to the bridge's longitudinal axis. Using this method, both local damage and global damage in the bridge reveal themselves as having a localized effect on the bridge response. Furthermore, damage is revealed in such a way that it enables differentiation of the damage types. To demonstrate the effectiveness of the method, modal parameters were extracted from acceleration data obtained from a finite element model of a full bridge. Analysis of the modal parameters showed that the proposed approach could not only detect both local and global bridge damage, but could also differentiate between damage types using only one mode shape. The proposed method was compared to a previously developed SHM method.
\end{abstract}

\section{Introduction}

Structural health monitoring (SHM) has gained considerable attention in recent years as a tool used to monitor the health state of civil infrastructure. It is based on the understanding that physical or mechanical degradation will change a structure's performance over time [1]. Most dynamic SHM methods are based on a set of vibration measurements acquired in the time domain. These measurements are then transformed to the frequency domain where they are used to identify damage directly (i.e., frequency response function methods), or indirectly through the derived modal parameters of the structure [2]. In the latter, damage is identified through a comparison of either the modal parameters, or structural models based on the modal parameters, before and after damage [3]. Ideally, information about the location and extent of damage can be used to determine the remaining useful life of the structure. To date, a multitude of experimental and numerical research investigations have been performed in damage identification. A comprehensive review of this work can be found in the literature [4-8]. With this in mind, the following literature survey will focus only on those research efforts immediately relevant to the proposed work, that is, damage identification methods that rely on direct comparison of the modal parameters before and after damage.

In order to detect and locate damage in a structure, extracted modal parameters are often applied to different damage indices. The indices are formed by direct comparison of the modal parameters or through application of mathematical equations that relate the modal parameters to a physical characteristic of the structure, at different time instances in the life-cycle of the structure. The most easily determined modal parameter of a structure is its natural frequencies. As a result, a significant body of work has been dedicated to investigate the feasibility of using shifts in natural frequencies as a damage indicator [8]. While there has been some success using these methods to identify damage in small laboratory 
structures, their suitability for damage identification in fullscale structures is uncertain [2].

Although changes in the natural frequencies may be useful for detecting damage, it is a more difficult task to locate damage using this index. That is because the natural frequencies do not correlate directly with the spatial characteristics of the structure, thereby making it difficult to relate a change in the natural frequencies to the location of damage. On the other hand, mode shapes contain information about the spatial characteristics of the structure, and local damages are reflected through changes at the corresponding locations in the mode shapes. As a result, several different damage indices have been developed based on the changes in the mode shapes before and after damage. A comprehensive review of these indices can be found in the literature $[2,4-8]$.

The effect of structural damage on the absolute difference between mode shapes has been observed in simple-supported and analytical beam models with a single localized damage location [9]. The results reveal a peak in the mode shape difference at the location of the damage for certain modes and models, although the peak is always accompanied by an increase in the mode shape difference at another location not in the region of the damage. The effect of damage on the change in mode shapes of a prestressed concrete bridge has been reported to be small but significant, with an increase in damage resulting in an increase in the observed changes [10]. However, the changes in mode shape were not always confined to the damaged area of the bridge. A simple index for detecting damage using mode shapes is to take the relative difference (RD) between scaled mode shapes from the undamaged and damaged structure. Numerical and experimental studies on a simple beam-like structure have shown that single local damage can be located when the index is calculated from modes whose frequency is affected by the damage [11]. A subsequent study showed that the RD index was adequate for numerical investigations of a cantilevered beam with single and multiple local damage locations but was not capable of predicting a 50\% uniform reduction in the beam modulus [12]. It was also concluded that the performance of the RD index was poor for experimental data obtained from a simply supported beam with single and multiple local damage locations. The RD index has also been used for damage detection and location in off-shore platforms. In an experimental investigation using a scale model of a well platform, it was observed that the RD index was affected by structural damage in the load-bearing braces [13]. Not only was the magnitude of the change in the mode shape dependent on the severity of the damage, but also the changes in the mode shapes occurred very near to the damage location. A later study also using small-scale models of offshore platforms confirmed that the RD index was sensitive to damages imposed in the structural members and was capable of identifying the region of damage in most cases [14].

Other research has focused on using incomplete mode shapes to detect and locate damage in a two-dimensional truss structure [15]. The damage sites are first identified approximately using incomplete mode shapes; then, the true location and extent of the damage are determined using modal frequencies. As an alternative to using the displacement mode shapes to detect and locate damage, the rotation of mode shapes has also been investigated as an indicator of damage in cantilever and simply supported plates [16]. The rotation of the mode shape is calculated as the derivative of the displacement mode shape and is shown numerically to be more effective than the latter in locating damage at the plate supports. A neural network-based technique has been proposed for damage assessment of structures using mode shape differences as the input [17]. The effectiveness of the method was demonstrated numerically for a simple beam and a multigirder bridge model with multiple localized damage sites. In a later study, a novel statistical algorithm has been presented to extract a damage indicator based on the difference in mode shapes before and after damage in timber beam specimens [18]. Laboratory results show that the peak values of the damage indicators calculated from the first two modes were sensitive to different damage severities and locations and were also reliable when multiple localized damages were present in the beams.

Another damage indicator based on the mode shapes before and after damage is the change in mode shape curvature index. The index is calculated by taking the difference between the curvature of the mode shapes determined from the undamaged and damaged structure, and peaks in the index indicate the location of the damage. The mode shape curvature index has been shown to be effective in detecting and locating damage in simple-supported and analytical beam models with a single localized damage location [9]. It is shown that the maximum difference in the index is localized only to the region of damage. A subsequent study involving an experimental cantilevered beam and a numerical simple-supported beam revealed that the mode shape curvature index was capable of identifying multiple damage locations in the beams [12]. However, similar to the $\mathrm{RD}$ index, the mode shape curvature index was determined to be unsatisfactory in detecting a uniform reduction in the global stiffness of the beam. Application of the mode shape curvature index to both numerical and experimental data for a three-span steel stringer bridge demonstrated that the index correctly identified the most severe damage scenario but was inconsistent for the less severe damage cases considered $[19,20]$. In addition, it was shown that the index gave falsepositive indications of damage when applied to data sets obtained from the undamaged bridge.

Numerical simulation of a simple-supported and continuous (two-span) beam model has revealed that the mode shape curvature index is generally more accurate using lower modes when the first five modes of vibration were considered [21]. For the simple-supported beam model with a single damage location, it was concluded that the first mode will provide the most reliable index in the presence of a limited number of sensors. However, it is observed that multiple modes are necessary for locating damage in the continuous beam model when more than one damage location is present. Similar observations were also made in a subsequent study using beam models with the same support conditions and comparable damage scenarios [22]. The mode shape curvature method has also been investigated for detecting 
and locating damage in carbon/epoxy composite beams with damage due to a saw-cut, impact, and delamination of the composite layers [23]. Experimental results show that the index was capable of correctly identifying all damage except for two cases of delamination.

Additional research efforts have been made to determine the optimal sampling rate to minimize the effect of measurement noise and truncation error on the calculation of the displacement mode shapes used in the mode shape curvature index [24]. Formulas for the optimal sampling interval are provided along with their numerical verification. Later research combined fuzzy logic with the mode shape curvature index for identifying the location and size of damage in a FE model of a cantilever beam [25]. It was determined that the method was successful in accurately determining the location of damage, but quantifying the size of damage was more difficult. Finally, it was shown that vertical bending and torsional modes, as well as transverse bending modes, could be successfully extracted from a twospan reinforced-concrete triple box-beam bridge for use in calculating irregularities in mode shape curvatures [26]. It is suggested that the transverse bending modes, which are formed from response data measured in the plane of the bridge deck, could be used in damage identification schemes for bridges. However, no actual damage detection was performed using the extracted modes.

The previously described damage indices depend on differences in the modal parameters of the damage and undamaged structure for damage identification. The damage locating vector (DLV) technique is a different approach that localizes damage using load distributions for which the static response of a structure is the same in the undamaged and damaged state [27]. Some of the favorable features of the technique are its generality with respect to structure type, its effectiveness for structures with single and multiple damage occurrences, and its reliance solely on measured data. Another damage identification scheme uses the local flexibility in the damage identification scheme [28]. In this method, the flexibility matrix determined from modal parameters is combined with a virtual load to identify regions of nonzero stress in a structure. It is shown that these regions correspond to locations where a potential change in local stiffness has occurred. The local flexibility method is modelindependent and capable of damage detection, localization, and quantification. It has been suggested that improvements in damage identification can be achieved through improved signal processing using wavelet transforms. A review of the state-of-the-art of wavelet transforms for use in structural health monitoring can be found in the literature [29]. Damage identification using discrete wavelet transforms has been performed for beams, plate-type structures, and multistory building structures to good effect [30-32].

After a comprehensive review of the available literature related to damage identification methods, the following observations have been made: (1) the majority of research studies, both numerical and experimental, consider idealized structures such as simple-supported, cantilevered, or continuous beam models to evaluate damage indices, (2) there are a limited number of studies using a full-bridge, and these are primarily based on the steel stringer bridge-type, (3) generally, only localized damage representing a loss of stiffness in a member or change in support condition is considered in the test structure, (4) in almost all numerical studies, loss of stiffness is modeled as a reduction in the modulus at discrete location(s) in the structure, (5) in some studies where global damage of the member was considered, damage indicators were not effective in identifying damage, and (6) there was no single damage index that works effectively for all structure types and damage scenarios.

In the present work, a new method is proposed for detecting, locating, and differentiating between different damage types in a prestressed concrete adjacent box-beam bridge. The method is based on the change in the first vertical mode extracted from the transverse direction of the bridge. The mode is determined through application of modal curve fitting to frequency response functions (FRFs) that are formed using vertical response data obtained in the direction perpendicular to the bridge's longitudinal axis. The proposed method is hereafter referred to as the change in first transverse mode (CFTM) index. To the best of the authors' knowledge, this is the first time a damage index has been formed using the vertical mode extracted from the transverse direction of a bridge structure, although it should be noted that transverse bending modes (in the plane of the bridge deck) have been identified in the past for use in damage identification for bridges [26]. The advantage of formulating the proposed index in the transverse direction is that damage that has a global effect on the bridge's response in the longitudinal direction reveals itself as a localized effect in the transverse direction. At the same time, local damage still reveals itself as a localized effect. As a result, both local damage and global damage have a localized effect on the index, thereby making it easier to detect and locate damage in the bridge. It will also be shown that different types of damage affect the index differently, thereby also making it possible to differentiate between different damage types. This is particularly important for adjacent box-beam bridges, which are subject to local and global damage in the box beams, as well as global damage in the transverse load transfer mechanism (i.e., shear key).

In the work that follows, the proposed CFTM index will be evaluated for a prestressed concrete adjacent boxbeam bridge with several different combinations of simulated damage types. The damage types will include local and global damage to the bridge. Global damage will be represented as a loss of stiffness in critical bridge components over the entire length of the bridge, while local damage will be limited to localized sections of beams only. Both damage types will be modeled as a reduction in the modulus of elasticity. While the effects of global reductions in modulus are easily understood, the effects of localized reductions are less intuitive. In order to better relate the effect of local reductions in modulus to the global bridge behavior, the derivation of an equivalent modulus will be presented. The equivalent modulus will be used in subsequent portions of the paper to help quantify local damage in the full-bridge structure in global terms. With the equivalent modulus established, the effectiveness of the CFTM method for damage identification will be 


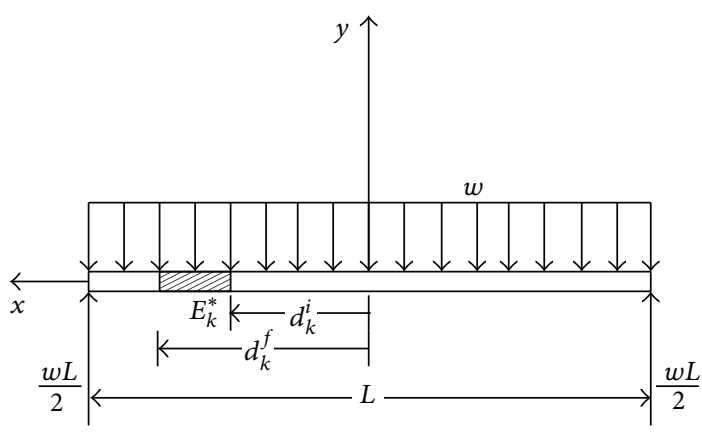

(a)

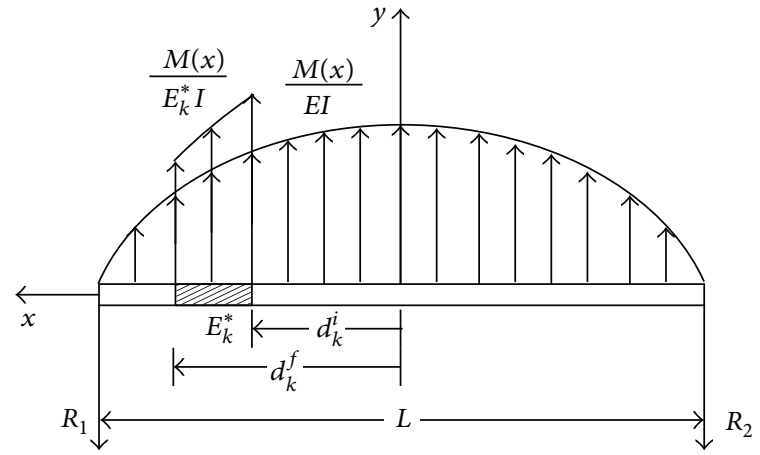

(b)

FIGURE 1: Schematic showing (a) simply supported beam with uniformly distributed load and (b) loading on conjugate beam.

determined for a prestressed concrete adjacent box-beam bridge model subject to several different combinations of simulated local and global damage, and the results will be compared with another commonly used mode-based damage index: the change in uniform load surface curvature (ULSCurvature) index.

\section{Equivalent Modulus}

The purpose of establishing the equivalent modulus is to relate the effect of a localized reduction in bending stiffness in a bridge member to the global behavior of the bridge. However, the effect that a local reduction in a single member has on the overall bridge behavior is not easily determined. This is due, in part, to the fact that the overall bridge behavior is a function not only of the properties of its individual members, but also of how those members interact under load. For the same reason, the effect of a global reduction in bending stiffness for a single member of the bridge on the overall bridge behavior is also not well understood. However, the effect of a global reduction in bending stiffness for a single, simple-supported, symmetrically loaded beam is easy to conceptualize, particularly in terms of the mid-span static deflection. From basic principles, it can be shown that the mid-span static deflection of such a beam will increase proportionately relative to a global reduction in the bending stiffness. On the contrary, the same cannot be said for a local reduction in bending stiffness within the same beam. Instead, the increase in mid-span static deflection of a beam with a local reduction in bending stiffness will depend on the magnitude and location of the reduction, and the length over which the stiffness of the beam is reduced. Therefore, the objective of the following is to relate one or more local reductions in bending stiffness in a beam to an overall global reduction.

Consider the single, simply supported prismatic beam with uniformly distributed load $w$ as shown in Figure 1(a). The beam has length $L$, moment of inertia $I$, and modulus of elasticity $E$. The beam is subject to a local reduction in modulus in the $k$ th section which begins and ends at distances $d_{k}^{i}$ and $d_{k}^{f}$ measured from mid-span, respectively.
The length $l_{k}$ over which the reduction occurs may then be defined as $l_{k}=d_{k}^{f}-d_{k}^{i}$. The new modulus of the reduced section is denoted by $E_{k}^{*}$. It should be noted that all distances are measured positively according to the coordinate system shown. In order to derive an expression for the mid-span deflection using the conjugate beam method, it is necessary to load the conjugate beam with $M(x) / E I$ from the real beam as shown in Figure 1(b). The moment from the real beam is expressed as a function of the distance $x$ as follows:

$$
M(x)=-\frac{w x^{2}}{2}+\frac{w L^{2}}{8}
$$

From Figure 1(b), the effect of the reduced modulus $E_{k}^{*}$ on the real beam is an increase in loading on the conjugate beam at the same location. In order to determine an expression for the mid-span deflection in the real beam with reduced modulus $E_{k}^{*}$, the mid-span moment on the conjugate beam is derived. To simplify the derivation, the principle of superposition is applied and the loading on the conjugate beam is represented as the sum of the loadings shown in Figure 2. Figure 2(a) represents the conjugate loading for the real beam with no local reduction in modulus, while Figure 2(b) represents the additional conjugate loading due to $E_{k}^{*}$. The deflection in the real beam with no local reduction in modulus may then be calculated as:

$$
\delta=\frac{5 w L^{4}}{384 E I}
$$

while the deflection in the real beam due to $E_{k}^{*}$ is taken as the mid-span moment on the conjugate beam shown in Figure 2(b). The resulting expression for the mid-span moment due to a local reduction in modulus in the $k$ th section is

$$
M_{k}=\frac{1}{2} P_{k}^{*} c_{k}^{*}-\frac{1}{2} P_{k} c_{k}-\frac{1}{2} \frac{L}{2} P_{k}^{*}+\frac{1}{2} \frac{L}{2} P_{k}
$$




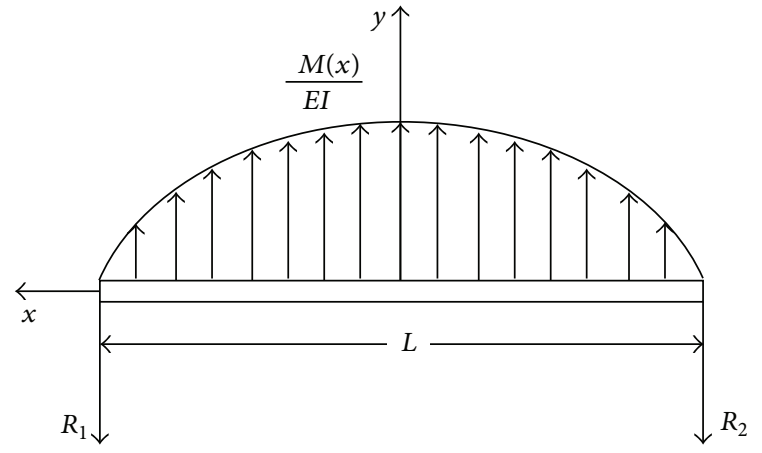

(a)

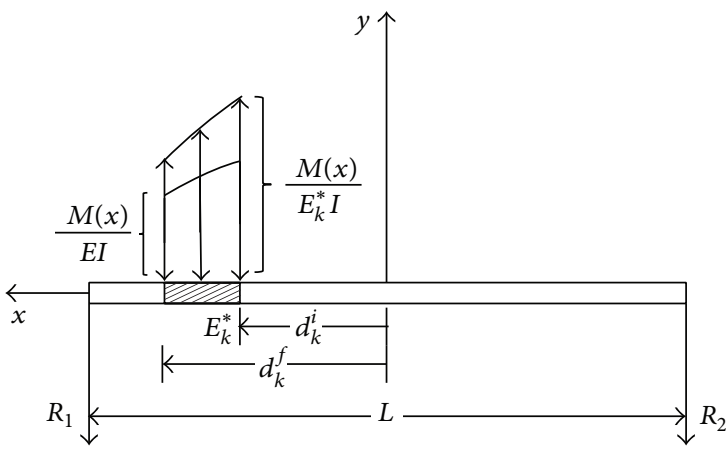

(b)

FIGURE 2: Schematic showing (a) conjugate beam loading for the real beam with no local reduction in modulus and (b) additional conjugate loading due to $E_{k}^{*}$.

where

$$
\begin{aligned}
P_{k} & =\int_{d_{k}^{i}}^{d_{k}^{f}} \frac{M(x)}{E I} d x \\
& =\frac{w}{E I}\left[\left(\frac{\left(d_{k}^{i}\right)^{3}}{6}-\frac{\left(d_{k}^{f}\right)^{3}}{6}\right)-\left(\frac{d_{k}^{i}}{8}-\frac{d_{k}^{f}}{8}\right) L^{2}\right], \\
c_{k} & =\frac{1}{P} \int_{d_{k}^{i}}^{d_{k}^{f}} x \frac{M(x)}{E I} d x \\
& =\frac{1}{P} \frac{w}{E I}\left[\left(\frac{\left(d_{k}^{i}\right)^{4}}{8}-\frac{\left(d_{k}^{f}\right)^{4}}{8}\right)-\left(\frac{\left(d_{k}^{i}\right)^{2}}{16}-\frac{\left(d_{k}^{f}\right)^{2}}{16}\right) L^{2}\right], \\
P_{k}^{*} & =\frac{E}{E_{k}^{*}} P_{k}, \\
c_{k}^{*} & =\frac{P_{k}}{P_{k}^{*}} \frac{E}{E_{k}^{*}} c_{k}=c_{k} .
\end{aligned}
$$

Substituting (4) into (3) and with some rearranging, the midspan moment on the conjugate beam due to a local reduction in modulus in the $k$ th section may be expressed as

$$
\begin{aligned}
M_{k}=\frac{1}{2} \frac{w}{E I}\left(\frac{E}{E_{k}^{*}}-1\right) \\
\times\left\{\left[\left(\frac{\left(d_{k}^{i}\right)^{4}}{8}-\frac{\left(d_{k}^{f}\right)^{4}}{8}\right)-\left(\frac{\left(d_{k}^{i}\right)^{2}}{16}-\frac{\left(d_{k}^{f}\right)^{2}}{16}\right) L^{2}\right]\right. \\
\left.-\left[\left(\frac{\left(d_{k}^{i}\right)^{3}}{6}-\frac{\left(d_{k}^{f}\right)^{3}}{6}\right)-\left(\frac{d_{k}^{i}}{8}-\frac{d_{k}^{f}}{8}\right) L^{2}\right] \frac{L}{2}\right\} .
\end{aligned}
$$

The mid-span deflection on the real beam is taken as the negative of the mid-span moment on the conjugate beam to keep consistent with the convention in (2) and may be expressed more conveniently as

$$
\delta_{k}^{*}=\frac{w}{384 E I} \frac{\Delta E_{k}^{*}}{E_{k}^{*}}\left(24 A_{k}-16 L B_{k}-12 L^{2} C_{k}+12 L^{3} D_{k}\right),
$$

where

$$
\begin{gathered}
\Delta E_{k}^{*}=E-E_{k}^{*}, \quad A_{k}=\left(d_{k}^{f}\right)^{4}-\left(d_{k}^{i}\right)^{4}, \\
B_{k}=\left(d_{k}^{f}\right)^{3}-\left(d_{k}^{i}\right)^{3}, \quad C_{k}=\left(d_{k}^{f}\right)^{2}-\left(d_{k}^{i}\right)^{2}, \\
D_{k}=d_{k}^{f}-d_{k}^{i} .
\end{gathered}
$$

Finally, the total mid-span deflection on the real beam due to $m$ sections with reduced modulus may be determined by summing the mid-span deflections due to the individual sections as follows:

$$
\delta^{*}=\frac{w}{384 E I} \sum_{k=1}^{m} \frac{\Delta E_{k}^{*}}{E_{k}^{*}}\left(24 A_{k}-16 L B_{k}-12 L^{2} C_{k}+12 L^{3} D_{k}\right) .
$$

It should be noted that, for simplicity, (8) was derived for sections with reduced modulus located to the left of midspan. Sections located to the right of mid-span should be mirrored onto the left side, and (8) should be applied accordingly.

The sum of the expressions for the mid-span deflections in (2) and (8) gives the total deflection for a single, simply supported prismatic beam with uniformly distributed load containing $m$ sections with reduced modulus. As stated previously, a beam with local reductions in modulus will provide a mid-span deflection which can also be represented by an equivalent beam with a uniform equivalent modulus. The mid-span deflection of the beam with equivalent modulus $E_{\text {eq }}$ can be determined in accordance with (2) as

$$
\delta_{\text {eq }}=\frac{5 w L^{4}}{384 E_{\text {eq }} I} \text {. }
$$


An expression for the equivalent modulus may now be derived by setting the mid-span deflection in (9) equal to the sum of the mid-span deflections from (2) and (8) giving

$$
\begin{aligned}
E_{\mathrm{eq}}=5 L^{4} & \\
\qquad & \times\left(\frac { 1 } { E } \left[5 L^{4}+\sum_{k=1}^{m} \frac{\Delta E_{k}^{*}}{E_{k}^{*}}\left(24 A_{k}-16 L B_{k}-12 L^{2} C_{k}\right.\right.\right. \\
& \left.\left.\left.+12 L^{3} D_{k}\right)\right]\right)^{-1}
\end{aligned}
$$

Equation (10) may now be used to calculate the equivalent modulus for a beam with one or more sections with a local reduction in modulus. However, local reductions in modulus in the literature are usually expressed in terms of percent reductions in the original modulus. The percent reduction in the original modulus based on the equivalent modulus in (10) may be expressed as

$$
\begin{aligned}
\% \Delta E_{\mathrm{eq}}= & \left(\frac{E-E_{\mathrm{eq}}}{E}\right) \times 100 \\
= & {\left[\sum_{k=1}^{m} \frac{\Delta E_{k}^{*}}{E_{k}^{*}}\left(24 A_{k}-16 L B_{k}-12 L^{2} C_{k}+12 L^{3} D_{k}\right)\right.} \\
& \times\left(5 L^{4}+\sum_{k=1}^{m} \frac{\Delta E_{k}^{*}}{E_{k}^{*}}\left(24 A_{k}-16 L B_{k}-12 L^{2} C_{k}\right.\right. \\
& \left.\left.\left.+12 L^{3} D_{k}\right)\right)^{-1}\right] \times 100 .
\end{aligned}
$$

Equation (11) may now be used to quantify the effect of local reductions in modulus in a single, simply supported beam with uniformly distributed load in terms of a percent reduction in the uniform modulus of an equivalent beam with the same mid-span static deflection. It is important to note that the expression in (11) is unique to the assumptions made regarding the loading, support conditions, and geometry of the beam and that alternate expressions would have to be derived if these assumptions changed. However, the advantage to using the assumptions of uniformly distributed loading on a simply supported prismatic beam is that these conditions are easy to conceptualize, as they are consistent with a beam having uniform cross section, supported at both ends, and supporting its own self-weight.

It should be noted that the preceding derivation of the equivalent modulus is based on elastic behavior of the beam model. However, the presence of damage in actual beams could lead to the formation of plastic hinges and inelastic beam behavior. In such a case, the equivalent modulus presented in (10) would not be directly applicable, as it does not account for the increase in mid-span deflections associated with inelastic bending. It could, however, be taken as a conservative estimate of the modulus of the damaged beam. It is also worth pointing out that the purpose of the equivalent modulus is to relate the effect of a local reduction in beam modulus to global beam behavior, and it is particularly useful in numerical damage identification research where beams/structures are often treated as elastic even in the presence of a locally reduced modulus.

\section{Damage Indices}

The CFTM index is formed by taking the absolute value of the relative difference between the scaled first vertical modes measured in the transverse direction of the before and after damage bridge, or

$$
\{\mathrm{CFTM}\}=\left|\frac{\left\{\phi_{T}\right\}-\left\{\phi_{T}\right\}^{*}}{\left\{\phi_{T}\right\}}\right|,
$$

where the subscript $T$ indicates that the modes are calculated in the transverse direction of the bridge and the asterisk indicates modes from the damaged state. As stated earlier, the advantage of using vertical modes calculated in the transverse direction is that global damage in the longitudinal direction of the bridge will reveal itself as localized damage, while local damage will still have a localized effect on the index. Furthermore, it will be shown that different types of damage have a unique effect on the CFTM index, thereby allowing for differentiation between damage types.

In the present work, the CFTM index will be compared with the change in uniform load surface curvature (ULSCurvature) index $[19,20,33,34]$. The change in ULSCurvature index is selected based on preliminary analyses in which it outperformed several other damage indices in identifying both local damage and global damage in a simply supported single-beam model [35]. The change in ULSCurvature index is calculated as the absolute value of the change in the curvature of the ULS calculated from the damaged and undamaged bridge; that is,

$$
\left\{\Delta \mathbf{U}_{\text {curv }}\right\}=\left|\left\{\mathbf{U}_{\text {curv }}\right\}-\left\{\mathbf{U}_{\text {curv }}^{*}\right\}\right| \text {. }
$$

The curvature of the ULS in (13) is calculated using the central difference approximation as follows:

$$
\left\{\mathbf{U}_{\text {curv }}\right\}=\frac{\left\{\mathbf{U}_{k+1}\right\}-2\left\{\mathbf{U}_{k}\right\}+2\left\{\mathbf{U}_{k-1}\right\}}{h^{2}},
$$

and the ULS is determined from the modal parameters of the bridge using

$$
\{\mathbf{U}\}=\sum_{j=1}^{m}\left[\frac{1}{(\omega)_{j}^{2 .}}\{\bar{\phi}\}_{j} \sum_{k=1}^{n}\left\{\bar{\phi}_{k}\right\}_{j}\right] .
$$

\section{Bridge Model}

In order to evaluate the CFTM index, a bridge model was developed based on the end span of a three-span prestressed adjacent box-beam bridge. The bridge was modeled after Fayette County Bridge No. 35-17-6.80 as shown in Figure 3(a), 


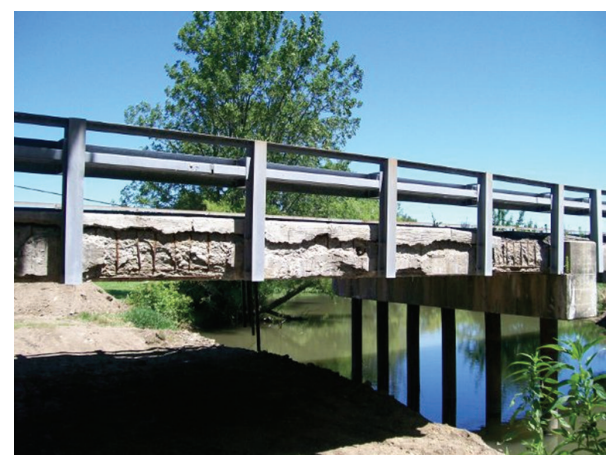

(a)

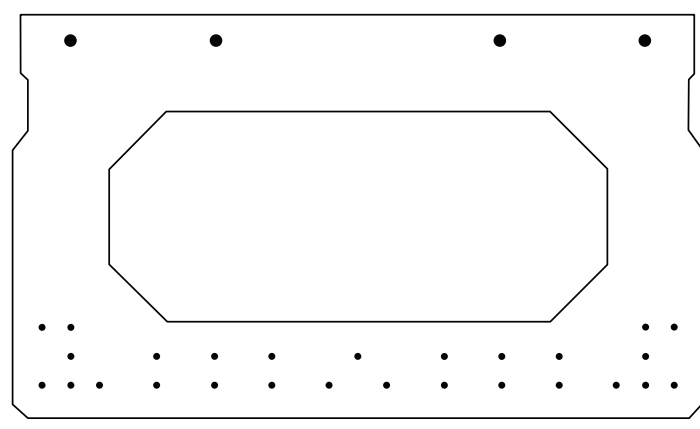

(b)

FIGURE 3: BR 35-17-6.80: (a) deterioration to the south side of end span and (b) typical cross section of box-beam.

which was a three-span continuous structure with equal span lengths of $14.6 \mathrm{~m}$ ( $47 \mathrm{ft}-10 \mathrm{in})$ sitting on a 15 degree skew. The two-lane bridge was $8.2 \mathrm{~m}(27 \mathrm{ft})$ wide and consisted of nine adjacent hollow-core box beams, $53.3 \mathrm{~cm}$ (21 in) deep by $91.4 \mathrm{~cm}$ (36 in) wide. The longitudinal steel included twenty-seven $9.5 \mathrm{~mm}$ (3/8 in) prestressed strands located in the bottom flange of the beams with four nonprestressed $15.9 \mathrm{~mm}$ rebar in the top flange, as shown in Figure 3(b). The prestressed steel was a seven-wire, $1.72 \mathrm{GPa}(250 \mathrm{ksi})$ strand. Shear reinforcement in the beam consisted of $12.7 \mathrm{~mm}$ stirrups. Transfer of load between adjacent beams was achieved through both tie rods and shear keys. Bridge 35-17-6.80 was constructed in 1967 and after 43 years of service, necessitated replacement. Replacement of the bridge occurred during the summer of 2010.

The bridge model was developed in SAP2000. The box beams were represented by a combination of beam and shell elements. Each beam element was assigned the crosssectional and material properties of the box beams. The modulus of concrete was taken to be $40.81 \mathrm{GPa}$ ( $5919 \mathrm{ksi}$ ) as determined during testing of the real bridge. The prestressed and nonprestressed steel in the beams were accounted for by transforming the cross section, resulting in an increase in each beam's overall moment of inertia from $10.34 \times 10^{-3} \mathrm{~m}^{4}$ $\left(24,851 \mathrm{in}^{4}\right)$ to $10.81 \times 10^{-3} \mathrm{~m}^{4}\left(25,961 \mathrm{in}^{4}\right)$. In order to keep the cross-sectional properties of the beam intact, a moment of inertia modifier was used. The beam elements were laid out on a grid representing the centerlines of all nine of the adjacent box beams. Each beam element spanned a length of $15.24 \mathrm{~m}(50 \mathrm{ft})$ and was supported with pin-pin configuration. Each line of beam elements was transversely spaced $91.44 \mathrm{~cm}$ (36 in) apart, representing each beam's centerline to centerline distance. In order to ensure that off center loads were transferred to the beams, area elements were laid overtop the beam elements with widths representing the width of the boxbeam cross section. Transverse load transfer is accounted for in the bridge model using linear springs with vertical stiffness to resist differential deflection between beams. Rotational stiffness due to continuity of the beams over the interior supports in the real bridge was accounted for using rotational springs at one end of the beam elements in the model. The springs only resist rotation about the strong-axis bending

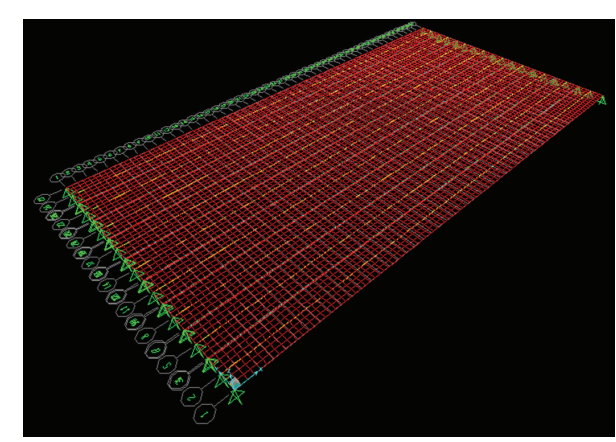

FIGURE 4: SAP model of end span of BR 35-17-6.80.

of the bridge. For obtaining the dynamic response, a modal damping ratio of $5 \%$ was assumed. Figure 4 shows the SAP model for the single span of BR 35-17-6.80.

Prior to demolition, full-scale nondestructive load testing on bridge BR 35-17-6.80 was completed [36]. The loaddeflection data was used to update the bridge model with respect to beam stiffness, shear key stiffness, and rotational stiffness at the interior support of the single span. During the first step of the model updating procedure, the shear key stiffness was determined by varying the stiffness of the vertical springs connecting adjacent beam elements. The optimal shear key stiffness was selected to minimize the differences in the differential deflections of adjacent beams between the model and real bridge. Once the shear key stiffness was determined, the stiffness of the rotational springs and the beam stiffness were modified in order to match the deflections between the bridge model and the actual bridge. The stiffness of the rotational springs was increased uniformly until the deflections in the model approached the deflections measured in the field. The beam stiffness was adjusted by reducing the modulus from the value measured during testing $(40.81 \mathrm{GPa})$. The reduction in modulus was used to represent the loss of bending stiffness in the box beams of the real bridge over time. Figure 5 shows a comparison of the deflection ratios and actual deflections between the bridge model and the real bridge, and it demonstrates good agreement between the two sets of data. With the beam 


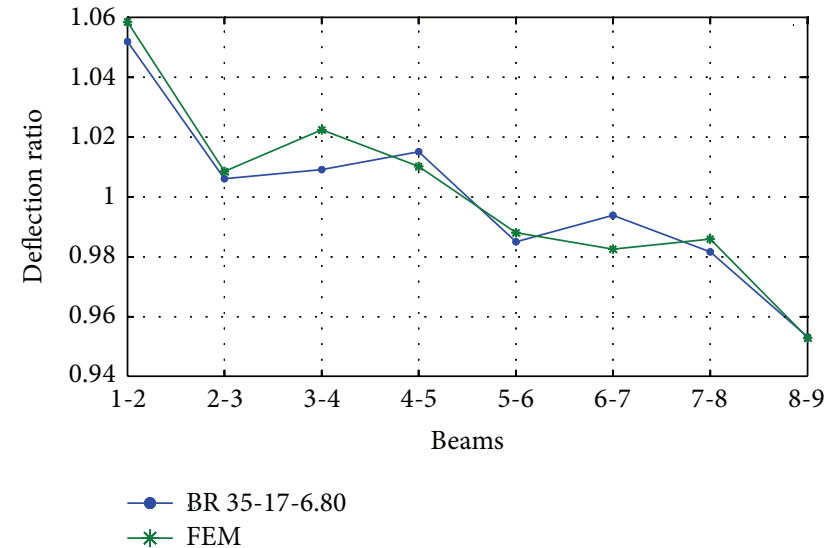

(a)

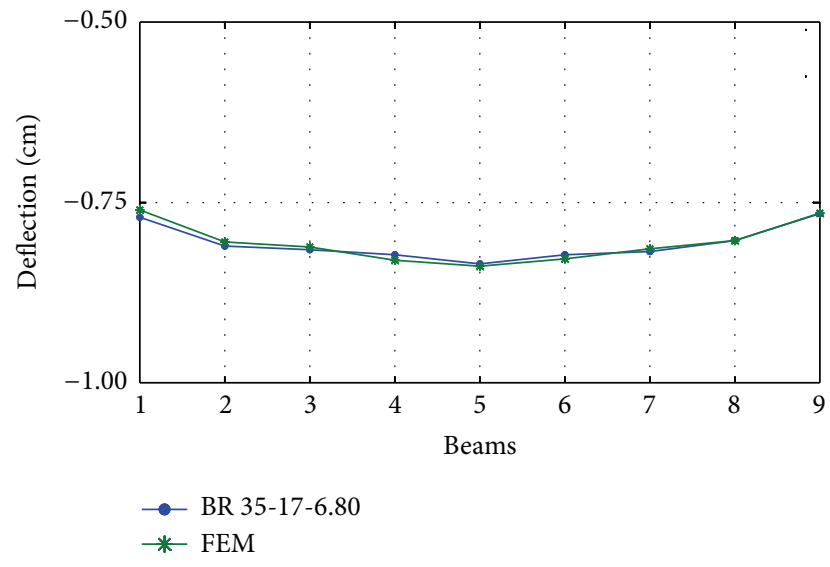

(b)

FIgURE 5: Comparison of (a) deflection ratios and (b) deflections for single span bridge model and end span of BR 35-17-6.80.

and shear key stiffness adjusted to reflect the load-deflection behavior of the real bridge, the rotational springs at the end of the bridge model were removed. The resulting single span bridge model with pinned end conditions was taken to represent the damaged state of the bridge and was used for analysis. In order to obtain an undamaged bridge model, the modulus of every beam, as well as the stiffness of every vertical spring, was taken to be the largest value determined from the damaged bridge model.

\section{Simulated Damage}

In addition to the damaged bridge model determined from the updating procedure described in Section 4, other combinations of local and global damage were also considered in order to evaluate the effectiveness of the proposed damage index for a variety of damage scenarios. These damage types were evaluated both individually and in combinations to assess the ability of the proposed index to detect, locate, and differentiate between the different types of damage. The local damage was simulated by reducing the modulus for finite lengths of beam elements, and it was representative of concrete spalling or deterioration of prestressing strands due to corrosion. The global damage consisted of both global beam damage and global shear key damage. The global beam damage was simulated by reducing the modulus uniformly for entire lengths of beams, and it was representative of full length member damage which would likely be caused from concrete degradation in the member. This type of damage was apparent in BR 35-17-6.80 as delamination between the top flange and the web had occurred for almost the entire length of one of the outside beams in the modeled span. For global shear key damage, the stiffness of the vertical springs was uniformly reduced. This type of damage could be attributed to corrosion or cracking of the shear keys between the beams. This type of damage was observed during loading of BR 35-17-6.80, as large differential deflections occurred between some beams. Several damage cases were considered based on combinations of local and global damage types and are listed in Table 1. It should be noted that shear key 2-3 represents the shear key between beams 2 and 3 .

The connecting elements representing the shear keys were assigned very large initial stiffness values. A significant reduction in the stiffness was required to achieve enough differential deflection between beam elements to represent the damaged shear keys. As a result, the percent reductions for the shear keys have been omitted from Table 1. However, it should be noted that the significant reductions are due to the modeling approach adopted, and the resulting differential deflections are representative of those measured during loading of the actual bridge.

\section{Modal Parameter Extraction}

Modal parameters for the bridge model were determined using forced vibration. The excitation was a chirp signal with a $4.45 \mathrm{kN}$ (1 kip) amplitude and frequency range of $2 \mathrm{~Hz}$ to $130 \mathrm{~Hz}$. The excitation was applied at the $10.67 \mathrm{~m}(35 \mathrm{ft})$ location on beam 5 . Vertical accelerations were obtained from the bridge model at nine locations distributed evenly along the lengths of the beam elements. A schematic representing the location at which the excitation was applied (indicated by red circle) and the response data was obtained (indicated by black dots) on the bridge model can be seen in Figure 6 . The sampling rate for the bridge response was $1000 \mathrm{~Hz}$. The vertical modes used in the calculation of the CFTM index were determined from response data taken in the transverse direction of the bridge at approximately $1.52 \mathrm{~m}$ $(5 \mathrm{ft})$ increments. The vertical modes used in the calculation of the change in ULS-Curvature index were determined from response data taken in the longitudinal direction of the bridge along each beam. Modal parameters were determined using the least squares complex exponential (LSCE) method.

\section{Results and Discussion}

7.1. Equivalent Modulus. In order to validate (10) for calculating the equivalent modulus $E_{\text {eq }}$, simulations were conducted 
TABLE 1: Damage cases for evaluating CFTM method.

\begin{tabular}{|c|c|c|c|c|}
\hline Case (1) & Type (2) & Component (3) & Location $(\mathrm{m})(4)$ & Reduction in modulus (\%) (5) \\
\hline 1 & Local & Beam 6 & $6.10-7.62$ & $10[2.3]$ \\
\hline 2 & Local & Beam 1 & $10.67-12.19$ & $50[8.3]$ \\
\hline 3 & Global & Beam 5 & $0-15.24$ & 10 \\
\hline 4 & Global & Beam 9 & $0-15.24$ & 50 \\
\hline \multirow{3}{*}{5} & \multirow{3}{*}{ Combination 1} & Beam 2 & $9.14-10.67$ & $50[13.3]$ \\
\hline & & Beam 5 & $1.52-3.05$ & $10[0.4]$ \\
\hline & & Beam 8 & $4.57-6.10$ & $25[4.8]$ \\
\hline \multirow{3}{*}{6} & \multirow{3}{*}{ Combination 2} & Beam 2 & $0-15.24$ & 25 \\
\hline & & Beam 4 & $6.10-7.62$ & $50[17.6]$ \\
\hline & & Beam 9 & $9.14-10.67$ & 10 [1.7] \\
\hline \multirow{3}{*}{7} & \multirow{3}{*}{ Combination 3} & Beam 2 & $0-15.24$ & 10 \\
\hline & & Beam 4 & $10.67-12.19$ & $25[2.9]$ \\
\hline & & Beam 9 & $0-15.24$ & 30 \\
\hline \multirow{3}{*}{8} & \multirow{3}{*}{ Combination 6} & Beam 3 & $3.05-4.57$ & $50[8.3]$ \\
\hline & & Beam 3 & $0-15.24$ & 25 \\
\hline & & Shear Key 6-7 & $0-15.24$ & - \\
\hline \multirow{3}{*}{9} & \multirow{3}{*}{ Combination 7 (BR 35-17-6.80) } & Beam 1 & $0-15.24$ & 30 \\
\hline & & Shear Key 2-3 & $0-15.24$ & - \\
\hline & & Shear Key 8-9 & $0-15.24$ & - \\
\hline
\end{tabular}

${ }^{*}$ Number in [] indicates percent reduction in equivalent modulus for local damage cases.

TABLE 2: Validation of equivalent modulus equation.

\begin{tabular}{|c|c|c|c|c|c|}
\hline \multirow{2}{*}{ Damage section (m) (1) } & \multicolumn{2}{|c|}{ Reduction in modulus (\%) } & \multicolumn{3}{|c|}{ Mid-span deflection $(\mathrm{cm})$} \\
\hline & Local (2) & Global equivalent (3) & Local (4) & Global equivalent (5) & Error (\%) (6) \\
\hline $1.52-3.05$ & 75 & 10.14 & -32.51 & -32.51 & $0.00 \%$ \\
\hline $3.05-4.57$ & 90 & 44.86 & -52.86 & -52.86 & $0.00 \%$ \\
\hline $4.57-6.10$ & 25 & 4.85 & -30.71 & -30.71 & $0.00 \%$ \\
\hline $6.10-7.62$ & 50 & 17.58 & -35.43 & -35.43 & $0.00 \%$ \\
\hline
\end{tabular}

in SAP2000 on a single beam model. The beam model was based on a single box beam from the undamaged model of BR 35-17-6.80 as described in Section 4. Several damage cases based on local reductions in the beam's modulus were considered and are shown in columns 1-2 of Table 2. For each local reduction in modulus, the equivalent global reduction in modulus is calculated using (10) (see column 3, Table 2). Then, the mid-span deflection of the single beam model with the local reduction in modulus, and the equivalent global reduction in modulus, is determined from SAP2000 for the same uniformly distributed loading. The results are presented in columns 4-6 of Table 2, and they show that the mid-span deflection using both moduli is the same.

7.2. Change in First Transverse Mode Method. In order to evaluate the effectiveness of the proposed CFTM index for damage identification, the full-bridge model was subjected to several damage cases where both single damage types and combinations of damage types were present (see Table 1). The individual damage types were comprised of single instances of local and global damage to a bridge beam, while the combinations included local and global beam damage, as well as shear key damage. For comparison, the change in ULSCurvature method was also calculated for the same damage cases. The results are discussed on a case-by-case basis in what follows.

7.2.1. Damage Case 1. The first damage case applied to the full-bridge model consists of a $10 \%$ reduction in modulus for

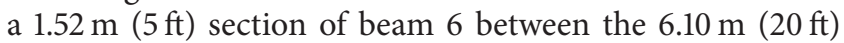
and $7.62 \mathrm{~m}(25 \mathrm{ft})$ locations $\left(\% \Delta E_{\mathrm{eq}}=2.3\right)$. Figure $7(\mathrm{a})$ shows the normalized CFTM $\left(\mathrm{CFTM}^{*}\right)$ index plotted versus beam number, where the CFTM index is normalized with respect to the peak value. Each curve in the plot represents the CFTM $^{*}$ index calculated at a different transverse location on the bridge (i.e., $1.52 \mathrm{~m}, 3.05 \mathrm{~m}, 4.57 \mathrm{~m}$, etc.). From Figure 7(a), it can be seen that peaks in the CFTM* index occur at beam 6. The two peaks are representative of the $6.10 \mathrm{~m}(20 \mathrm{ft})$ and $7.62 \mathrm{~m}$ ( $25 \mathrm{ft}$ ) locations surrounding the damage on beam 6 . The results show that the proposed CFTM* index was capable of accurately detecting and locating the damage. Figure $7(\mathrm{~b})$ shows the normalized change in ULS-Curvature $\left(\Delta U_{\text {curv }}^{*}\right)$ index plotted versus the distance along each beam, where the change in ULS-Curvature is normalized with respect to 


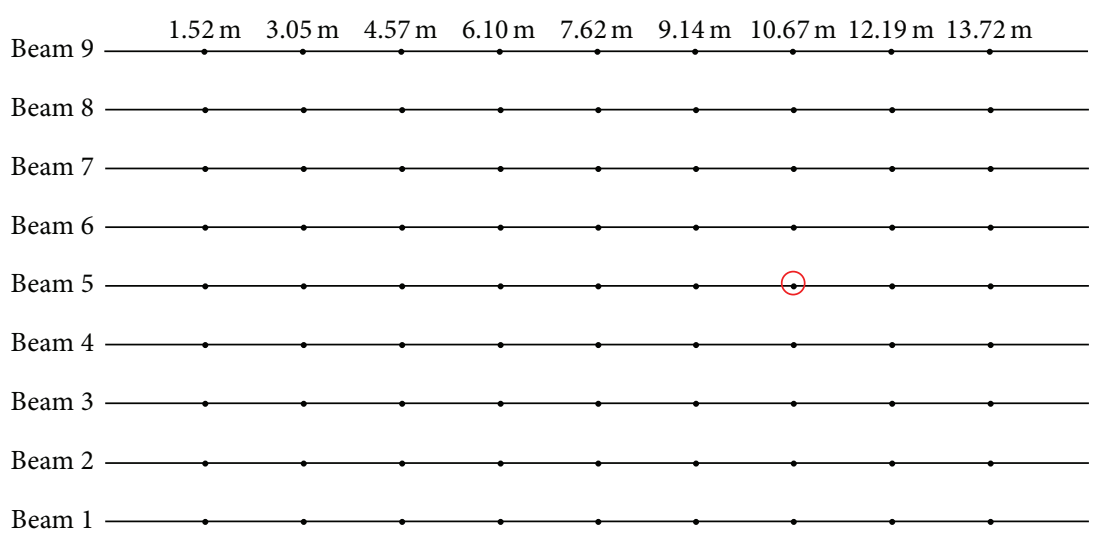

FIGURE 6: Schematic layout of data extraction locations.

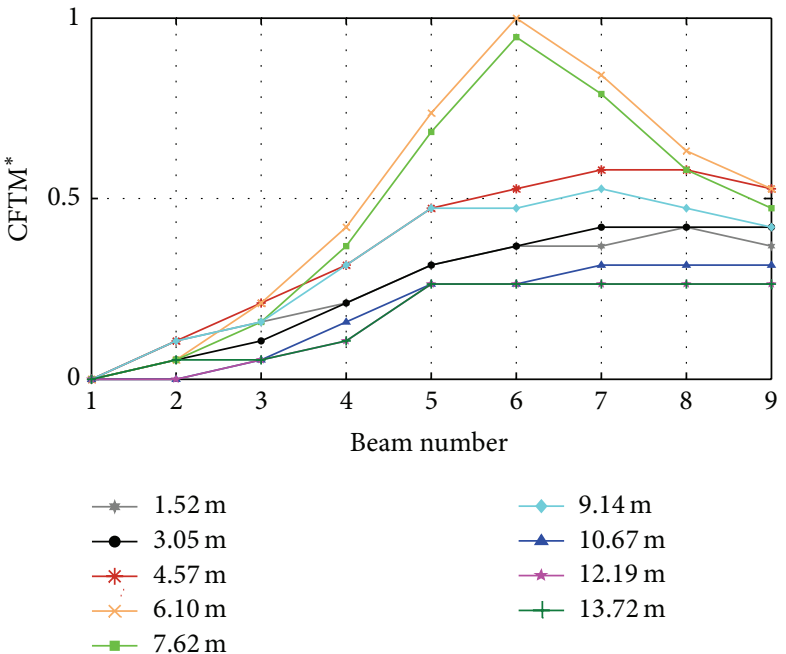

(a)

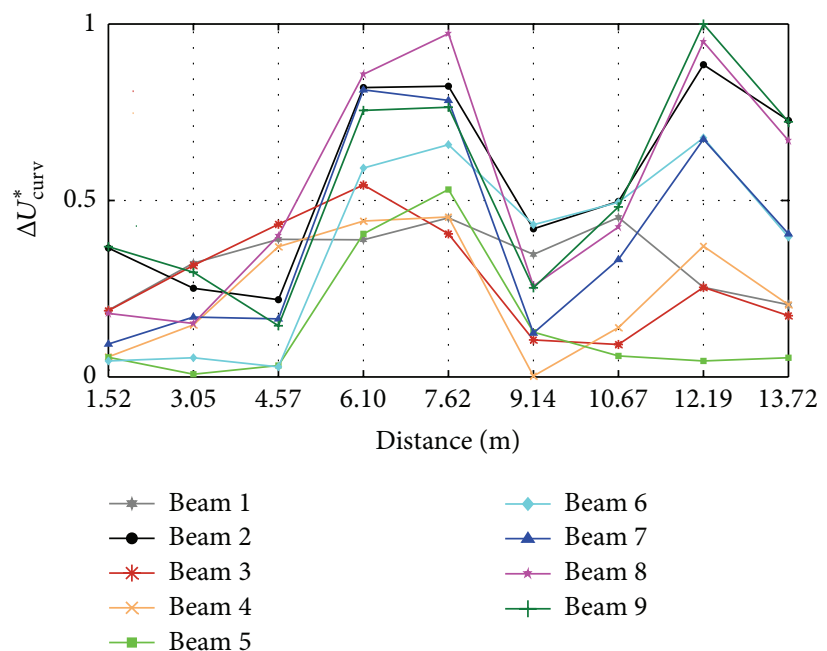

(b)

FIgURE 7: Plot of (a) CFTM ${ }^{*}$ and (b) $\Delta U_{\text {curv }}^{*}$ for damage case 1.

the peak value. Each curve in the plot represents the $\Delta U_{\text {curv }}^{*}$ index calculated for different beams in the bridge (i.e., beam 1, beam 2, etc.). From Figure 7(b), it can be seen that several curves peak between the $6.10 \mathrm{~m}(20 \mathrm{ft})$ and $7.62 \mathrm{~m}(25 \mathrm{ft})$ locations, and again at the $12.19 \mathrm{~m}(40 \mathrm{ft})$ location, but the curve corresponding to beam 6 does not exhibit the most significant change. The result would likely be interpreted as localized damage in beam 8 near the $7.62 \mathrm{~m}(25 \mathrm{ft})$ and $12.19 \mathrm{~m}$ (40 ft) locations. As a result, it would be difficult to identify and locate the damage in beam 6 using the $\Delta U_{\text {curv }}^{*}$ index.

7.2.2. Damage Case 2. Damage case 2 consists of a $50 \%$

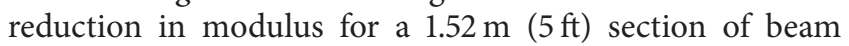

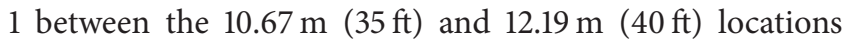
$\left(\% \Delta E_{\text {eq }}=8.3\right)$. Figure 8(a) shows the CFTM* index plotted versus beam number, and it can be seen that all of the curves in the plot show an increase near beam 1 . This can be attributed to the large reduction in modulus near the center of beam 1, which also influences the other beams in the bridge. However, the curves corresponding to the $10.67 \mathrm{~m}(35 \mathrm{ft})$ and

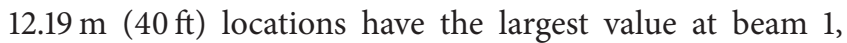
which is consistent with the applied damage case. Figure 8(b) shows the $\Delta U_{\text {curv }}^{*}$ index for damage case 2 . It is observed that the curve corresponding to beam 1 peaks at the $10.67 \mathrm{~m} \mathrm{(35 \textrm {ft } )}$ location and has its second largest value at the $12.19 \mathrm{~m}(40 \mathrm{ft})$ location. As a result, both the CFTM ${ }^{*}$ and the $\Delta U_{\text {curv }}^{*}$ indices are shown to be able to detect and locate the bridge damage.

7.2.3. Damage Case 3. Damage case 3 consists of a $10 \%$ reduction in beam 5 along the entire length of the beam. Figure 9(a) shows that all of the curves in the CFTM* index peak at beam 5 , thereby indicating that the method is capable of detecting and locating the global beam damage in the bridge. Figure 9 (b) shows the results using the $\Delta U_{\text {curv }}^{*}$ index. The curve corresponding to beam 9 has peaks at the $7.62 \mathrm{~m}(25 \mathrm{ft})$ and $12.19 \mathrm{~m}(40 \mathrm{ft})$ locations, while the curve corresponding to beam 5 represents one of the lower curves on the plot. This result would most likely be interpreted as local damage to beam 9 at the $7.62 \mathrm{~m}(25 \mathrm{ft})$ and $12.19 \mathrm{~m}$ 


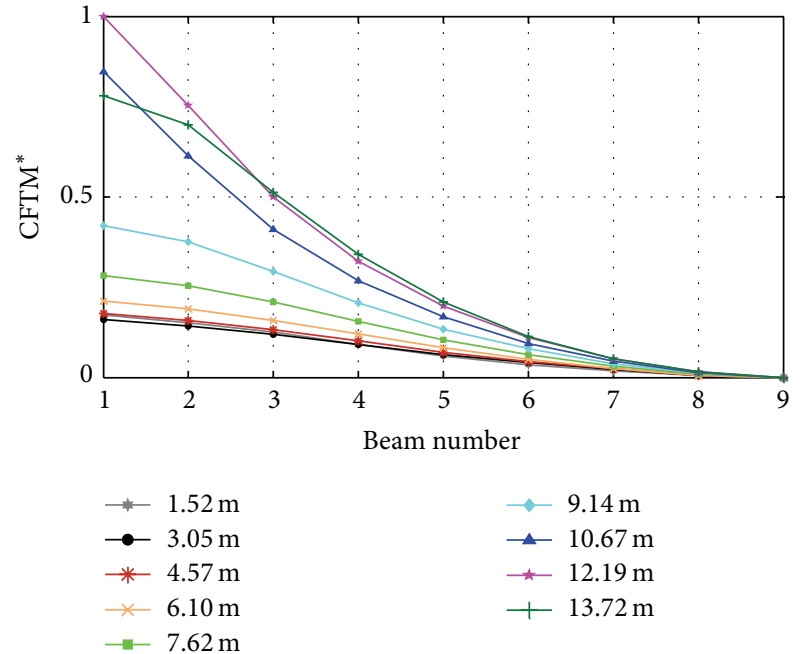

(a)

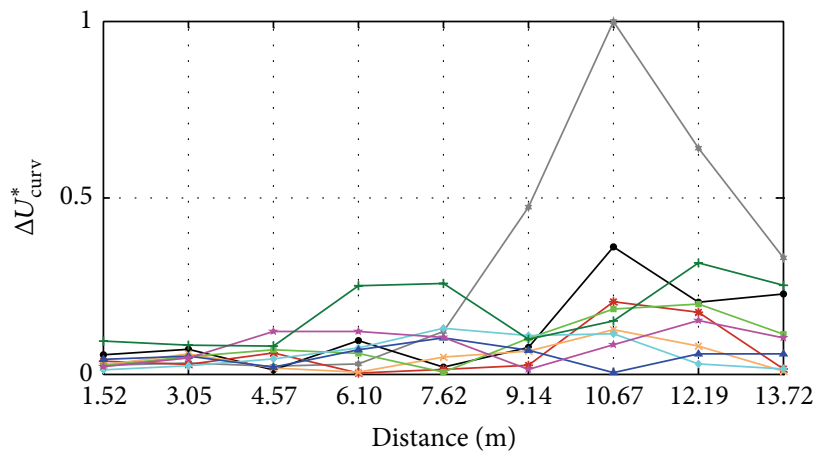

* Beam 1
$\rightarrow$ Beam 2
$*$ Beam 3
$\rightarrow$ Beam 4
$\rightarrow$ Beam 5

Figure 8: Plot of (a) CFTM* and (b) $\Delta U_{\text {curv }}^{*}$ for damage case 2.

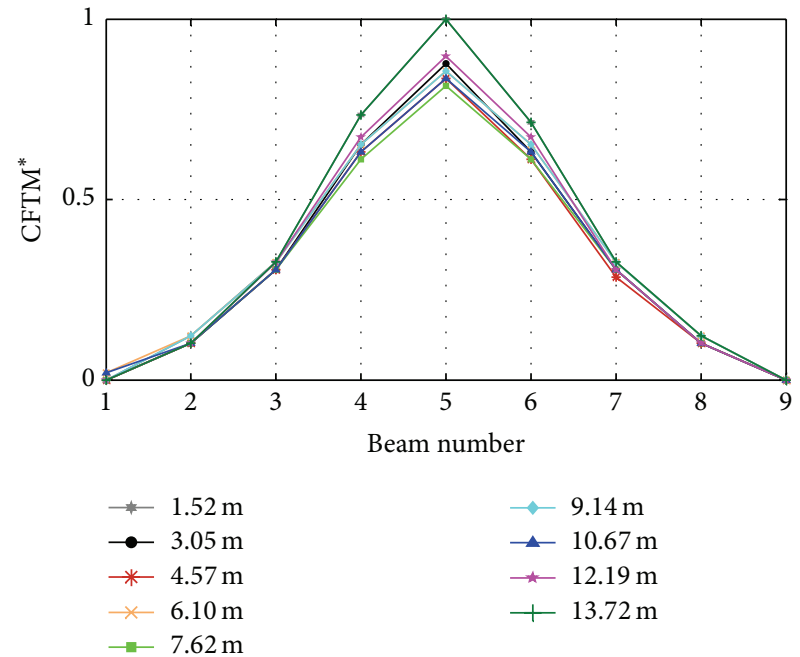

(a)
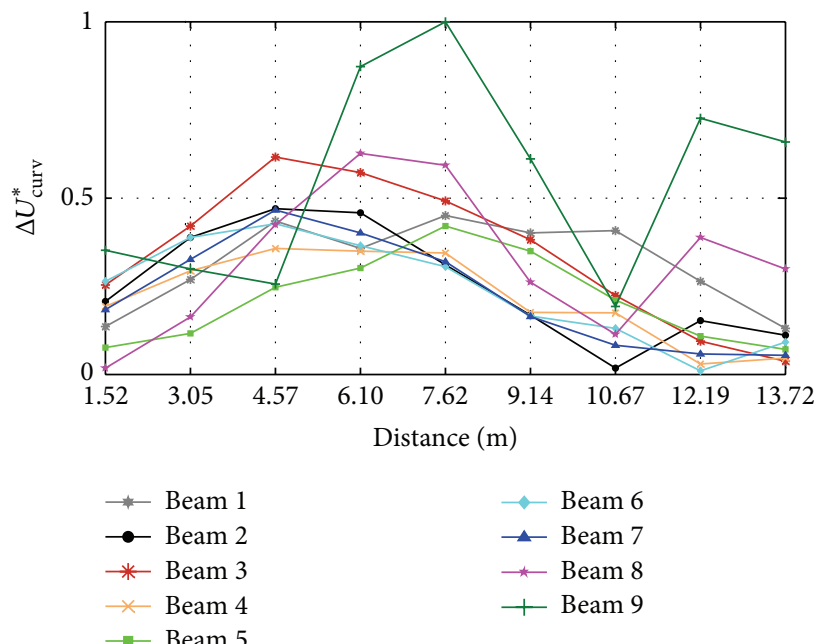

(b)

Figure 9: Plot of (a) CFTM ${ }^{*}$ and (b) $\Delta U_{\text {curv }}^{*}$ for damage case 3.

$(40 \mathrm{ft})$ locations, rather than damage along the entire length of beam 5 .

7.2.4. Damage Case 4. Damage case 4 represents another global beam damage case, with a $50 \%$ reduction in the modulus over the entire length of beam 9. Similar to damage case 3, Figure 10(a) shows that global beam damage reveals itself in the CFTM* ${ }^{*}$ index as an increase in all the curves near the damaged beam. Figure 10(b) shows the results using the $\Delta U_{\text {curv }}^{*}$ index. The curve corresponding to beam 9 has the largest peak value at the $6.10 \mathrm{~m}(20 \mathrm{ft})$ and $7.62 \mathrm{~m}(25 \mathrm{ft})$ locations, but it has the lowest values at the $3.05 \mathrm{~m}, 4.57 \mathrm{~m}$,

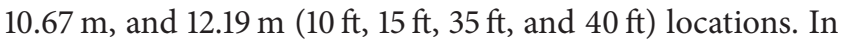
addition, the effect that the large global reduction in the beam 9 modulus has on the other beams in the bridge causes an increase in the curves corresponding to these beams. As a result, it becomes more difficult to identify that the damage is in beam 9. On the other hand, the effect of the large global reduction on other beams in the bridge contributes to the ability of the CFTM* index to detect and locate the beam damage (see Figure 10(a)).

7.2.5. Damage Case 5. Damage case 5 is a combination of three different local damages. It consists of a $50 \%$ reduction

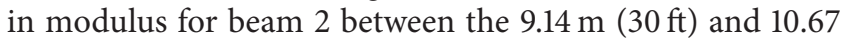
$(35 \mathrm{ft})$ locations $\left(\% \Delta E_{\mathrm{eq}}=13.3\right)$, a $10 \%$ reduction in modulus for beam 5 between the $1.52 \mathrm{~m}(5 \mathrm{ft})$ and $3.05 \mathrm{~m}(10 \mathrm{ft})$ locations $\left(\% \Delta E_{\mathrm{eq}}=0.4\right)$, and a $25 \%$ reduction in modulus for

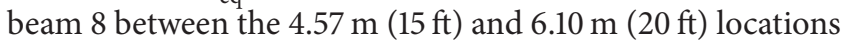
$\left(\% \Delta E_{\mathrm{eq}}=4.8\right)$. Figure 11(a) shows the results using the 


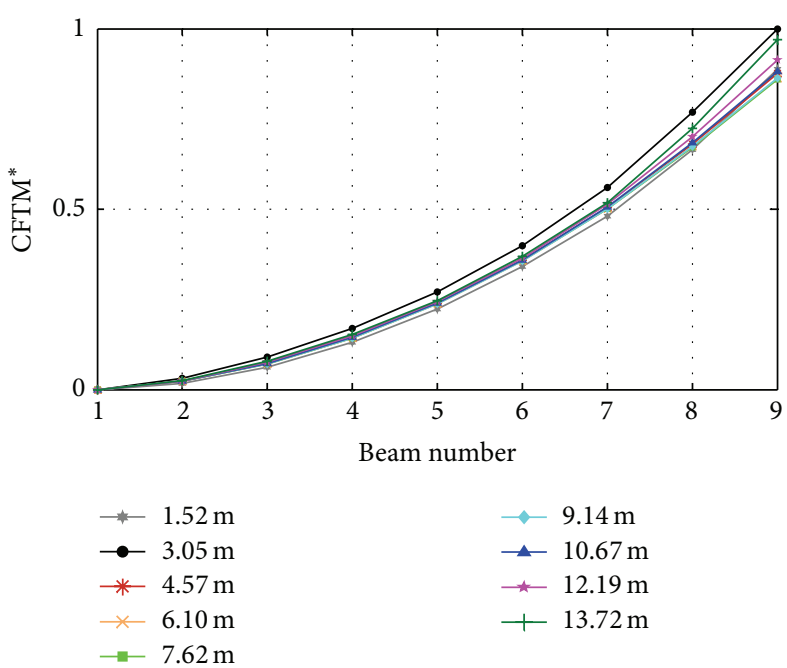

(a)

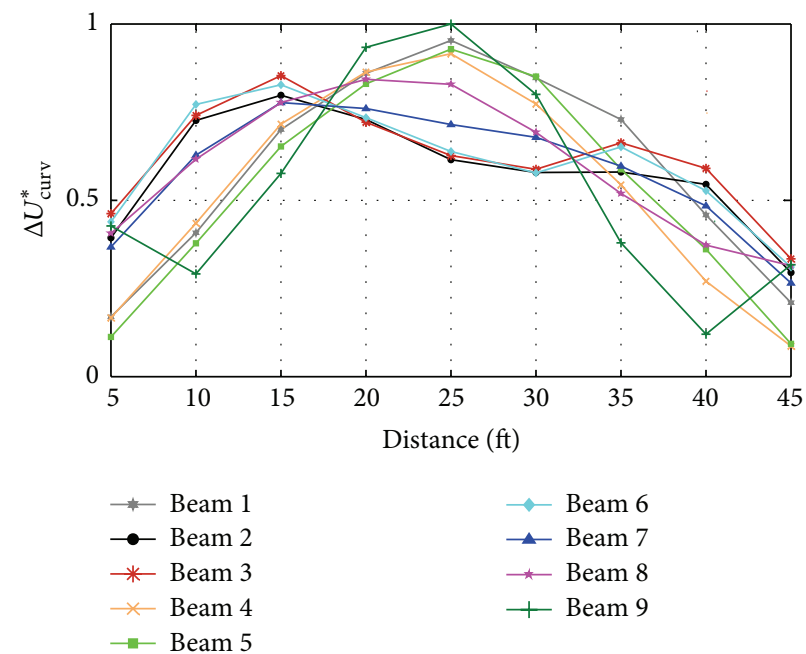

(b)

Figure 10: Plot of (a) $\mathrm{CFTM}^{*}$ and (b) $\Delta U_{\text {curv }}^{*}$ for damage case 4.

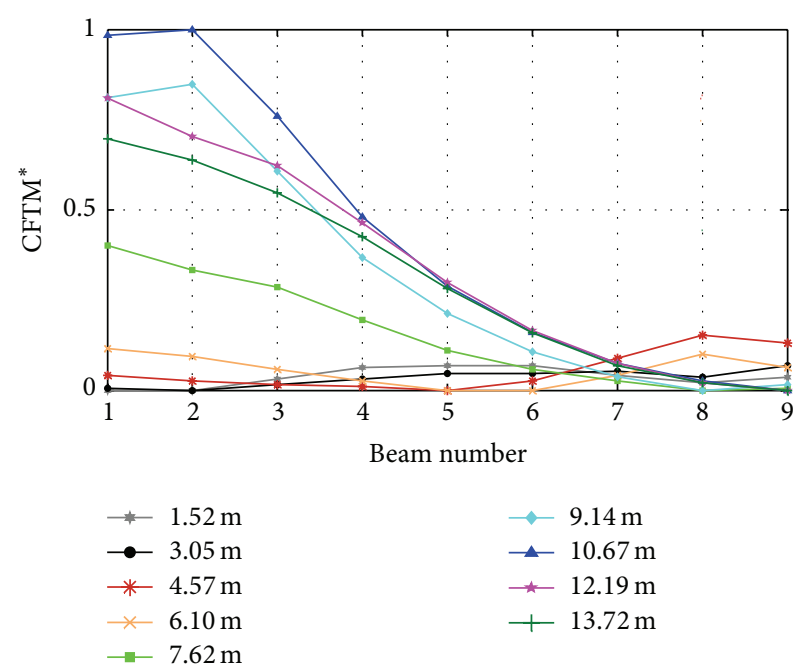

(a)

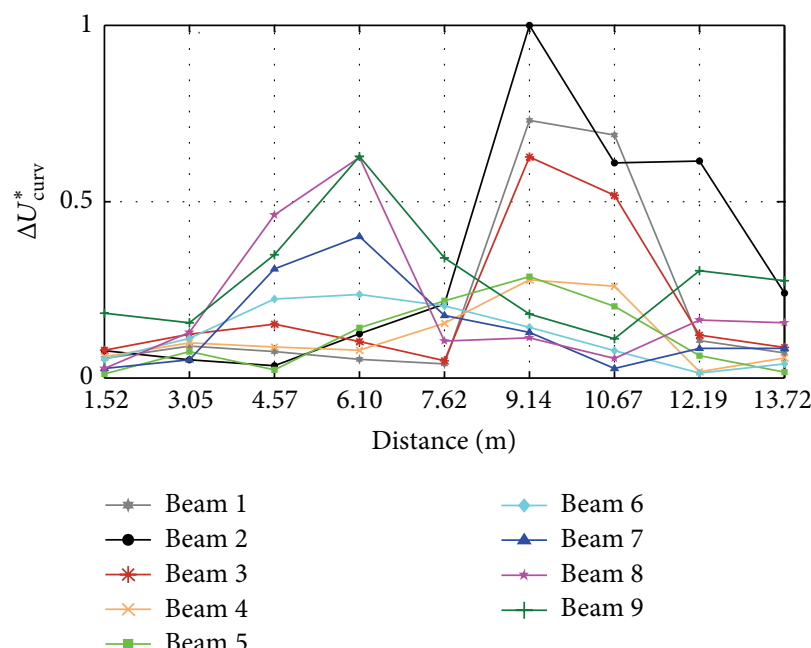

(b)

FIGURE 11: Plot of (a) CFTM ${ }^{*}$ and (b) $\Delta U_{\text {curv }}^{*}$ for damage case 5.

CFTM $^{*}$ index for damage case 5 . It can be seen that the two curves corresponding to the $9.14 \mathrm{~m}(30 \mathrm{ft})$ and $10.67 \mathrm{~m}(35 \mathrm{ft})$ locations peak at beam 2, the peak values are larger than those from any other curve, and the CFTM* index is capable of detecting and locating beam 2 damage. Similarly, the two curves corresponding to the $4.57 \mathrm{~m}(15 \mathrm{ft})$ and $6.10 \mathrm{~m}(20 \mathrm{ft})$ locations peak above the other curves in the plot at beam 8 , thereby detecting and locating the local damage in the beam. It is also possible to differentiate the curves corresponding to the $1.52 \mathrm{~m}(5 \mathrm{ft})$ and $3.05 \mathrm{~m}(10 \mathrm{ft})$ locations at beam 5 where the $10 \%$ reduction in modulus exists. However, there are several curves corresponding to other locations which have a larger value at beam 5 , thereby making it difficult to detect and locate the damage without prior knowledge of where the damage occurred. This can be attributed to the amount and location of damage in beam five, which has a relatively small effect on the overall bridge response when compared with the other damaged beams. Figure 11(b) shows the results for damage case 5 using the $\Delta U_{\text {curv }}^{*}$ index. There are

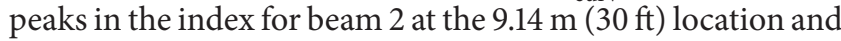

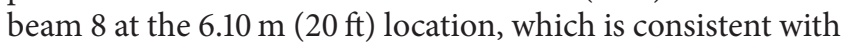
the damage in the bridge. However, the curve corresponding to beam 5 does not exhibit any significant change near the

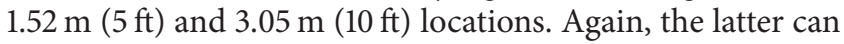
be attributed to the relatively small effect that the beam 5 damage has on the bridge.

7.2.6. Damage Case 6. Damage case 6 is a combination of two local damages and one global beam damage. The local damage consists of a $50 \%$ reduction in modulus for 


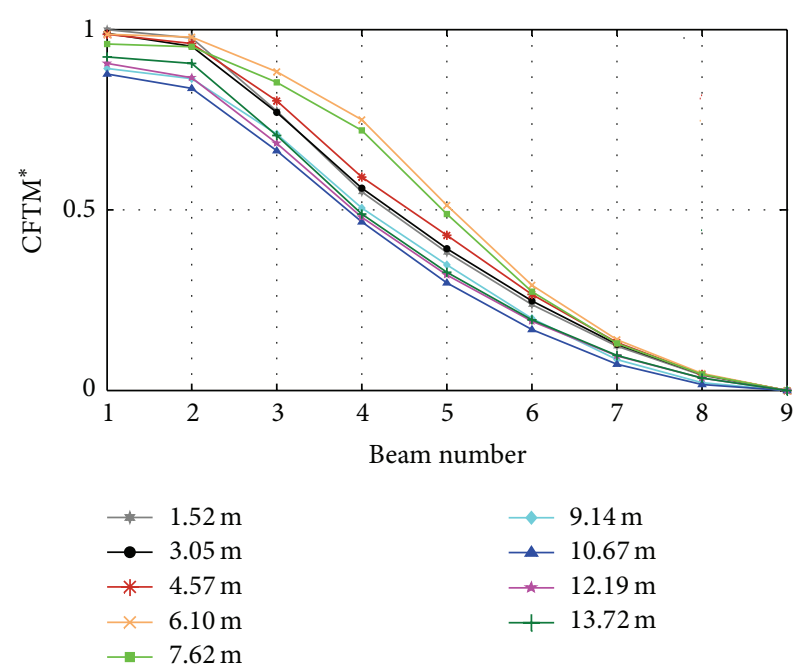

(a)

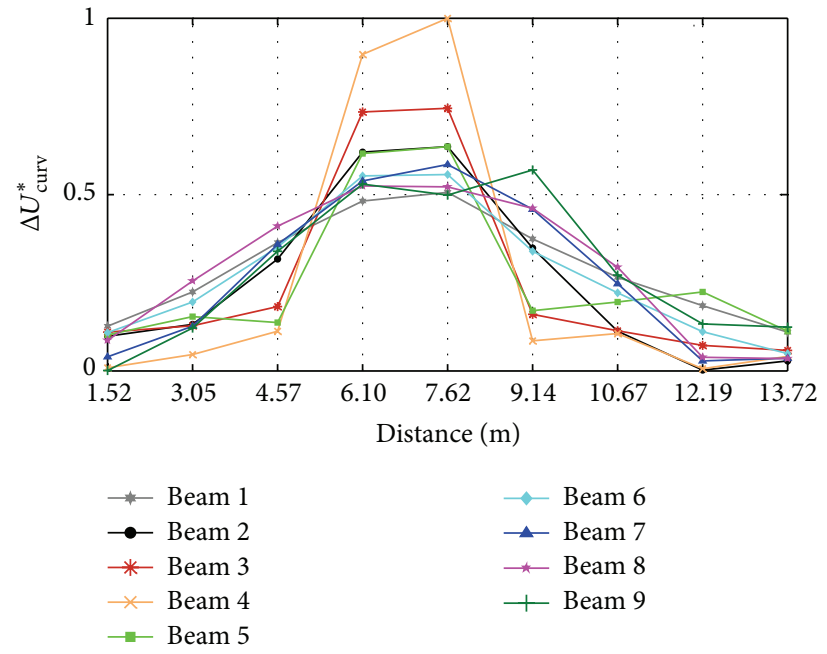

(b)

Figure 12: Plot of (a) CFTM ${ }^{*}$ and (b) $\Delta U_{\text {curv }}^{*}$ for damage case 6.

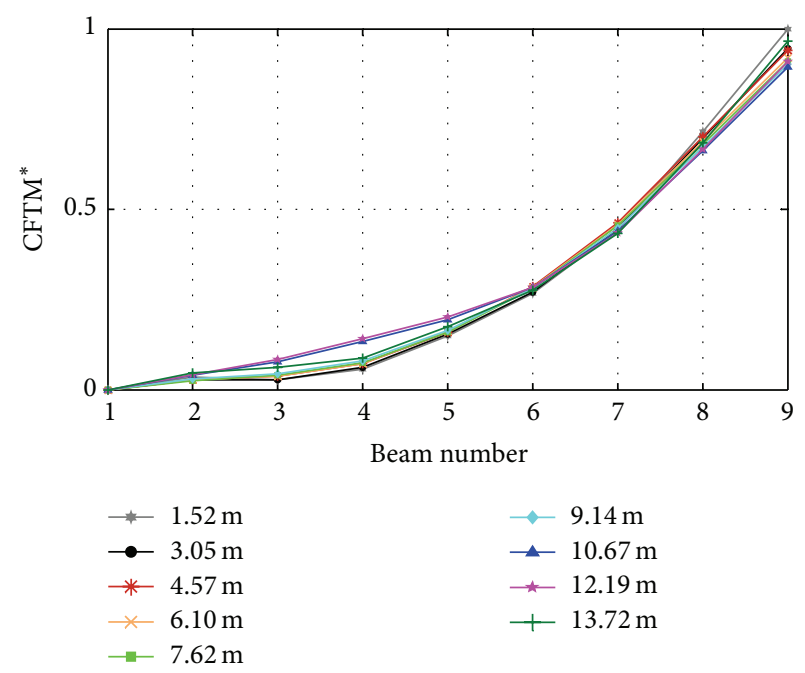

(a)

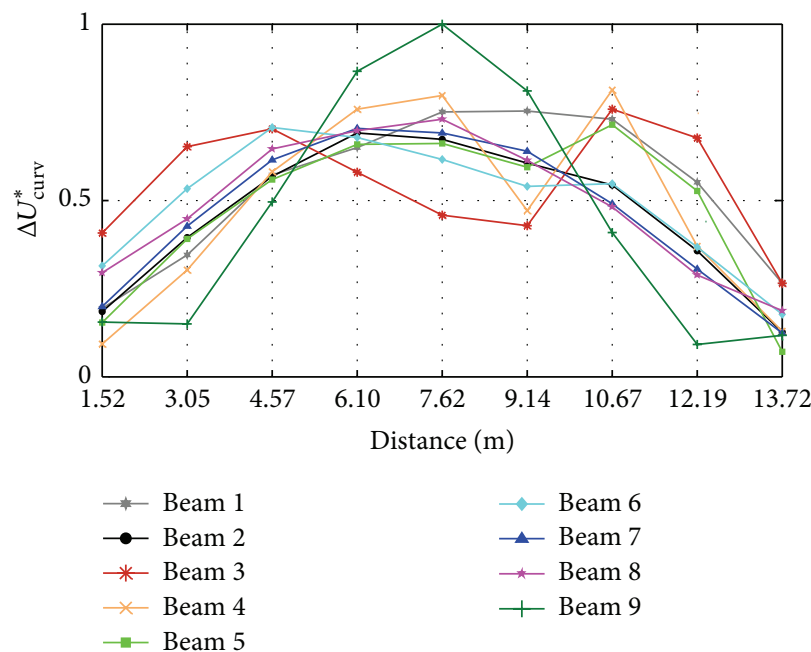

(b)

FIgURE 13: Plot of (a) CFTM* and (b) $\Delta U_{\text {curv }}^{*}$ for damage case 7.

beam 4 between the $6.10 \mathrm{~m}(20 \mathrm{ft})$ and $7.62 \mathrm{~m}(25 \mathrm{ft})$ locations $\left(\% \Delta E_{\mathrm{eq}}=17.6\right)$ and a $10 \%$ reduction in modulus for beam 9 at the $9.14 \mathrm{~m}(30 \mathrm{ft})$ and $10.67(35 \mathrm{ft})$ locations $\left(\% \Delta E_{\text {eq }}=1.7\right)$. The global damage is a $25 \%$ reduction in modulus along the entire length of beam 2. Figure 12(a) shows the results for the CFTM $^{*}$ index, which shows a peak in all curves near beam 2. Furthermore, the curves corresponding to the $6.10 \mathrm{~m}$ $(20 \mathrm{ft})$ and $7.62 \mathrm{~m}(25 \mathrm{ft})$ locations have larger values at beam 4 than the other curves in the plot. However, there is no detectable change in the index at beam 9. The latter can be attributed to the small influence that beam 9 damage has on the overall bridge response compared with the other beam damages. Figure 12(b) shows the results for the $\Delta U_{\text {curv }}^{*}$ index. There are peaks in the index for beam 4 at the $6.10 \mathrm{~m}(20 \mathrm{ft})$

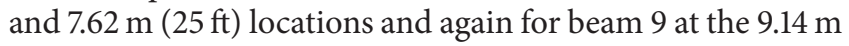

$(30 \mathrm{ft})$ location. However, the global damage in beam 2 is not clearly identifiable.

7.2.7. Damage Case 7. Damage case 7 consists of $10 \%$ and $30 \%$ reductions in modulus for the entire lengths of beams 2 and 9 and a $25 \%$ reduction in modulus between the $10.67 \mathrm{~m}(35 \mathrm{ft})$ and $12.19 \mathrm{~m}(40 \mathrm{ft})$ locations of beam $4\left(\% \Delta E_{\mathrm{eq}}=2.9\right)$. From Figure 13(a), it can be seen that all the curves in the plot of the CFTM $^{*}$ index peak at beam 9 , and the curves corresponding

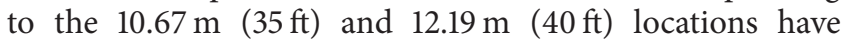
comparatively larger values at beam 4 . However, the global damage in beam 2 is not clearly identifiable, despite a small change in slope in all curves at this location. The change in slope is somewhat masked by the increase in value of the curves corresponding to the $10.67 \mathrm{~m}(35 \mathrm{ft})$ and $12.19 \mathrm{~m}(40 \mathrm{ft})$ 


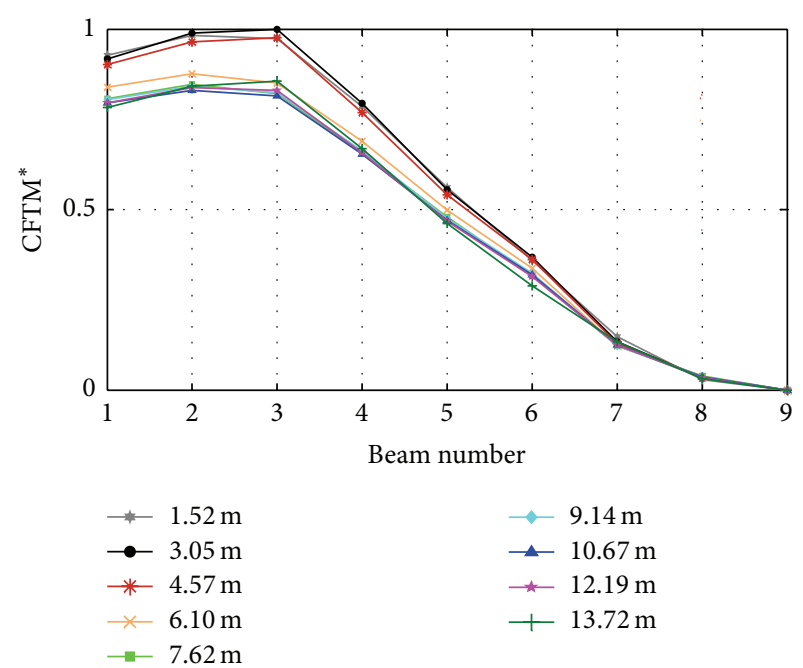

(a)

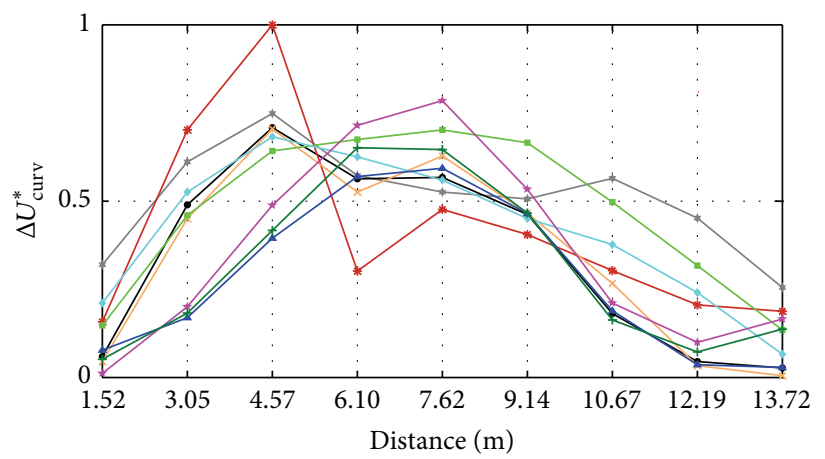

$*$ Beam 1
$\rightarrow$ Beam 2
$*$ Beam 3
$*$ Beam 4
$\rightarrow-$ Beam 5

$\rightarrow$ Beam 6

$\leftarrow$ Beam 7

* Beam 8

+ Beam 9

(b)

Figure 14: Plot of (a) $\mathrm{CFTM}^{*}$ and (b) $\Delta U_{\text {curv }}^{*}$ for damage case 8.

locations at beam 4 . Figure 13(b) reveals that the $\Delta U_{\text {curv }}^{*}$ index is capable of identifying the global damage to beam 9 and the local damage to beam 4 , but the global damage to beam 2 is not detected. However, it should be noted that there could be some confusion as to the interpretation of the results, as the curves for beams 1, 3, and 5 also peak at the $10.67 \mathrm{~m} \mathrm{(35 \textrm {ft } )}$ location with values just slightly lower than that for beam 4 .

7.2.8. Damage Case 8. Damage case 8 is a combination of local beam damage, global beam damage, and global shear key damage. The global beam damage consists of a $25 \%$ reduction in the modulus of beam 3 and is revealed in the CFTM $^{*}$ index as peaks in all of the curves at beam 3 , as shown in Figure 14(a). The local beam damage is represented by a $50 \%$ reduction in the modulus between the $3.05 \mathrm{~m}(10 \mathrm{ft})$ and $4.57 \mathrm{~m}(15 \mathrm{ft})$ locations in beam $3\left(\% \Delta E_{\mathrm{eq}}=8.3\right)$ and can be identified by the increase in value of the corresponding curves at beam 3 compared with the other curves in the plot. Finally, the global shear key damage in shear keys 6-7 (the key between beams 6 and 7) may be identified by the change in slope in all the curves between beams 6 and 7 . The results for the $\Delta U_{\text {curv }}^{*}$ index are shown in Figure 14(b) and indicate that the only damage that may be identified using this index is the

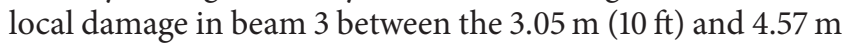
(15 ft) locations.

7.2.9. Damage Case 9. Damage Case 9 is a combination of global beam damage and two global shear key damages. The global beam damage consists of a $30 \%$ reduction in modulus for beam 1, and the shear key damages are in shear keys 2-3 and 8-9. From Figure 15(a), the global beam damage is clearly identifiable in the CFTM* index as all the curves in the plot peak at beam 1 . In addition, the shear key damage between keys 2 and 3 reveals itself as a change in slope of all the curves of the plot between beams 2 and 3. However, the shear key damage between keys 8 and 9 is not clearly identifiable in the plot. This may be attributed to the comparatively large influence that the global damage in beam 1 has on the overall response of the bridge. Figure 15(b) shows the results using the $\Delta U_{\text {curv }}^{*}$ index. There is a peak in the curve corresponding to beam 9 that could be interpreted as either local or global damage in that beam. There is no other identifiable damage in the bridge using this index. As a result, the $\Delta U_{\text {curv }}^{*}$ index falsely identifies the type of damage in the bridge associated with this damage case.

\section{Conclusions}

In the present work, a new damage identification method is proposed to detect, locate, and identify different damage types in a prestressed adjacent box-beam bridge. The method is based on the change in the first vertical mode extracted from the transverse direction of the bridge. The advantage of using the method is that both local bridge damage and global bridge damage are revealed as localized in the damage index. Furthermore, it is shown that different types of damage have a different effect on the index, thereby allowing for the differentiation of damage types. The method is demonstrated by obtaining vertical acceleration response data from a FE model of an actual bridge in the pre- and postdamage state. Several damage cases are considered that include local beam, global beam, and global shear key damage. The results obtained using the CFTM index are compared with those from another existing damage index, the change in uniform load surface (ULS) curvature.

It is shown that, for most damage cases, the CFTM index is capable of detecting, locating, and differentiating between the different damage types. However, there were some exceptions for low level damage where the effect of the damage was comparatively small on the overall bridge response. It should be noted that, in such cases, there was more significant damage in the bridge that was revealed through the index. 


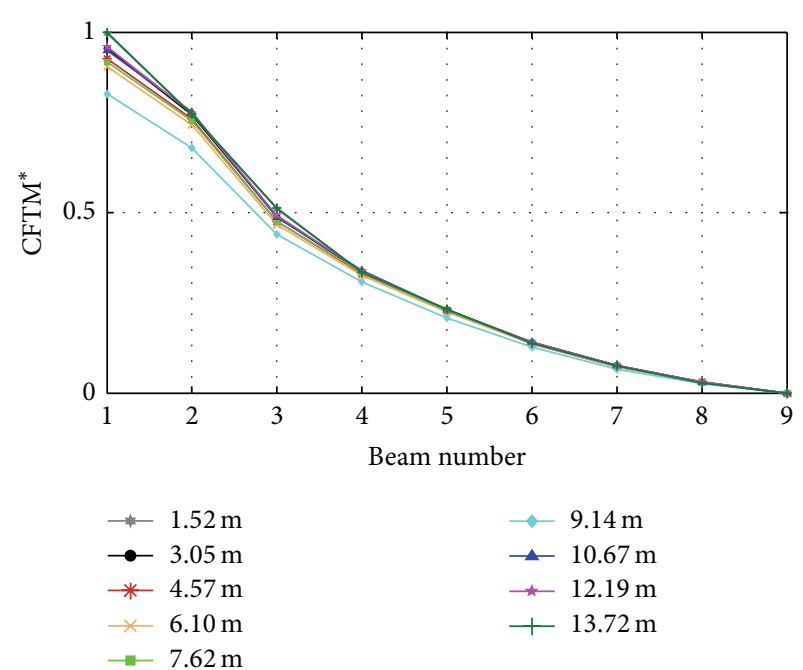

(a)

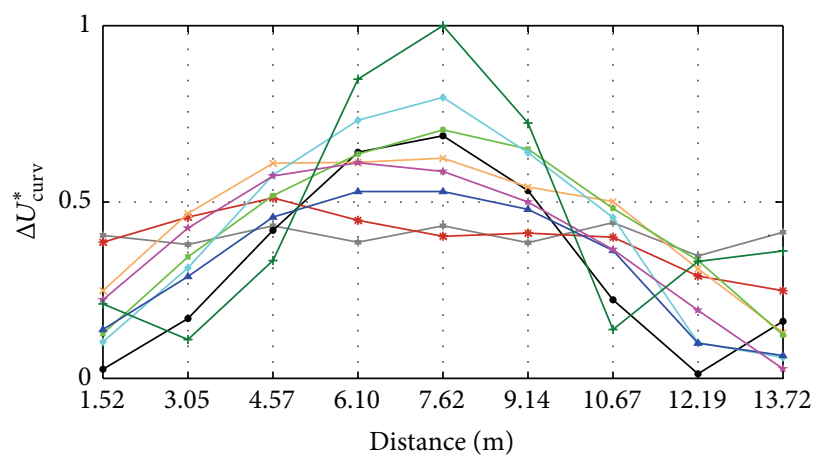

$\rightarrow$ Beam 1
$\rightarrow-$ Beam 2
$*$ Beam 3
$\rightarrow$ Beam 4
$\rightarrow-$ Beam 5

$\rightarrow$ Beam 6

$\sim$ Beam 7

* Beam 8

1 Beam 9

(b)

Figure 15: Plot of (a) $\mathrm{CFTM}^{*}$ and (b) $\Delta U_{\text {curv }}^{*}$ for damage case 9.

While an ideal damage index would identify all damage to the bridge, identifying the most significant damage would be of the highest priority. Comparison with the change in ULS-Curvature index showed that the CFTM index was able to provide a clearer picture of the damage in the bridge. Although the change in ULS-Curvature index was effective in locating most local damages and some global damage, it was not able to clearly identify the shear key damage, and sometimes it falsely identified damage in the bridge. Finally, it should be noted that in the present work the proposed CFTM method was evaluated for a particular type of bridge: the adjacent box-beam bridge. This type of bridge exhibits significant transverse stiffness, which could influence the effectiveness of the approach for damage identification. In addition, the calculation of the modal properties was performed in the absence of noise in the bridge response data. It is recognized that the inclusion of noise could have an adverse effect on the ability of the proposed method to accurately detect, locate, and identify damage in the bridge structure. Future work will focus on evaluating the CFTM method for other bridge types and using bridge response data with noise added at a reliable signal-to-noise ratio.

\section{Conflict of Interests}

The authors declare that there is no conflict of interests regarding the publication of this paper.

\section{References}

[1] C. R. Farrar and K. Worden, "An introduction to structural health monitoring," Philosophical Transactions of the Royal Society A: Mathematical, Physical and Engineering Sciences, vol. 365, no. 1851, pp. 303-315, 2007.

[2] E. P. Carden and P. Fanning, "Vibration based condition monitoring: a review," Structural Health Monitoring, vol. 3, no. 4, pp. 355-377, 2004.
[3] M. I. Friswell, "Damage identification using inverse methods," Philosophical Transactions of the Royal Society A: Mathematical, Physical and Engineering Sciences, vol. 365, no. 1851, pp. 393-410, 2007.

[4] P. C. Chang, A. Flatau, and S. C. Liu, "Review paper: health monitoring of civil infrastructure," Structural Health Monitoring, vol. 2, no. 3, pp. 257-267, 2003.

[5] W. Fan and P. Qiao, "Vibration-based damage identification methods: a review and comparative study," Structural Health Monitoring, vol. 10, no. 1, pp. 83-111, 2011.

[6] A. H. Gandomi, M. G. Sahab, A. Rahaei, and M. S. Gorji, "Development in mode shape-based structural fault identification technique," World Applied Sciences Journal, vol. 5, no. 1, pp. 2938, 2008.

[7] D. Montalvão, N. M. M. Maia, and A. M. R. Ribeiro, "A review of vibration-based structural health monitoring with special emphasis on composite materials," The Shock and Vibration Digest, vol. 38, no. 4, pp. 295-324, 2006.

[8] O. S. Salawu, "Detection of structural damage through changes in frequency: a review," Engineering Structures, vol. 19, no. 9, pp. 718-723, 1997.

[9] A. K. Pandey, M. Biswas, and M. M. Samman, "Damage detection from changes in curvature mode shapes," Journal of Sound and Vibration, vol. 145, no. 2, pp. 321-332, 1991.

[10] O. Huth, G. Feltrin, J. Maeck, N. Kilic, and M. Motavalli, "Damage identification using modal data: experiences on a prestressed concrete bridge," Journal of Structural Engineering, vol. 131, no. 12, pp. 1898-1910, 2005.

[11] C. H. J. Fox, "The location of defects in structures: a comparison of the use of natural frequency and mode shape data," in Proceedings of the 10th International Modal Analysis Conference (IMAC '92), pp. 522-528, San Diego, Calif, USA, 1992.

[12] O. S. Salawu and C. Williams, "Damage location using vibration mode shapes," in Proceedings of the 12th International Modal Analysis Conference, pp. 933-939, Honolulu, Hawaii, USA, 1994.

[13] V. G. Idichandy and C. Ganapathy, "Modal parameters for structural integrity monitoring of fixed offshore platforms," Experimental Mechanics, vol. 30, no. 4, pp. 382-391, 1990. 
[14] P. F. Viero and N. Roitman, "Application of some damage identification methods in offshore platforms," Marine Structures, vol. 12, no. 2, pp. 107-126, 1999.

[15] Z. Y. Shi, S. S. Law, and L. M. Zhang, "Damage localization by directly using incomplete mode shapes," Journal of Engineering Mechanics, vol. 126, no. 6, pp. 656-660, 2000.

[16] M. A. B. Abdo and M. Hori, "A numerical study of structural damage detection using changes in the rotation of mode shapes," Journal of Sound and Vibration, vol. 251, no. 2, pp. 227239, 2002.

[17] J. J. Lee, J. W. Lee, J. H. Yi, C. B. Yun, and H. Y. Jung, "Neural networks-based damage detection for bridges considering errors in baseline finite element models," Journal of Sound and Vibration, vol. 280, no. 3-5, pp. 555-578, 2005.

[18] C. Hu and M. T. Afzal, "A statistical algorithm for comparing mode shapes of vibration testing before and after damage in timbers," Journal of Wood Science, vol. 52, no. 4, pp. 348-352, 2006.

[19] C. R. Farrar and D. A. Jauregui, "Comparative study of damage identification algorithms applied to a bridge: I. Experiment," Smart Materials and Structures, vol. 7, no. 5, pp. 704-719, 1998.

[20] C. R. Farrar and D. A. Jauregui, "Comparative study of damage identification algorithms applied to a bridge: II. Numerical study," Smart Materials and Structures, vol. 7, no. 5, pp. 720-731, 1998.

[21] M. M. Abdel Wahab and G. de Roeck, "Damage detection in bridges using modal curvatures: application to a real damage scenario," Journal of Sound and Vibration, vol. 226, no. 2, pp. 217-235, 1999.

[22] A. Dutta and S. Talukdar, "Damage detection in bridges using accurate modal parameters," Finite Elements in Analysis and Design, vol. 40, no. 3, pp. 287-304, 2004.

[23] C. S. Hamey, W. Lestari, P. Qiao, and G. Song, "Experimental damage identification of carbon/epoxy composite beams using curvature mode shapes," Structural Health Monitoring, vol. 3, no. 4, pp. 333-353, 2004.

[24] E. Sazonov and P. Klinkhachorn, "Optimal spatial sampling interval for damage detection by curvature or strain energy mode shapes," Journal of Sound and Vibration, vol. 285, no. 4-5, pp. 783-801, 2005.

[25] M. Chandrashekhar and R. Ganguli, "Structural damage detection using modal curvature and fuzzy logic," Structural Health Monitoring, vol. 8, no. 4, pp. 267-282, 2009.

[26] R. Bolton, N. Stubbs, S. Park, S. Choi, and C. Sikorsky, "Measuring bridge modal parameters for use in non-destructive damage detection and performance algorithms," in Proceedings of the 17th International Modal Analysis Conference (IMAC '99), pp. 1269-1275, Orlando, Fla, USA, February 1999.

[27] D. Bernal, "Load vectors for damage localization," Journal of Engineering Mechanics, vol. 128, no. 1, pp. 7-14, 2002.

[28] E. Reynders and G. De Roeck, "A local flexibility method for vibration-based damage localization and quantification," Journal of Sound and Vibration, vol. 329, no. 12, pp. 2367-2383, 2010.

[29] M. M. Reda Taha, A. Noureldin, J. L. Lucero, and T. J. Baca, "Wavelet transform for structural health monitoring: a compendium of uses and features," Structural Health Monitoring, vol. 5, no. 3, pp. 267-295, 2006.

[30] A. Katunin, "Identification of multiple cracks in composite beams using discrete wavelet transforms," Scientific Problems of Machines Operation and Maintenance, vol. 2, no. 162, pp. 41-52, 2010.
[31] K. Sivasubramanian and P. K. Umesha, "Damage identification in beams using discrete wavelet transforms," International Journal of Civil and Structural Engineering, vol. 2, no. 3, pp. 950969, 2012.

[32] M. Masoumi and M. R. Ashory, "Damage identification in plate-type structures using 2-D spatial wavelet transform and flexibility-based methods," International Journal of Fracture, vol. 183, no. 2, pp. 259-266, 2013.

[33] D. Wu and S. S. Law, "Damage localization in plate structures from uniform load surface curvature," Journal of Sound and Vibration, vol. 276, no. 1-2, pp. 227-244, 2004.

[34] Z. Zhang and A. E. Aktan, "The damage indices for constructed facilities," in Proceedings of the 13th International Modal Analysis Conference, pp. 1520-1529, Society of Experimental Mechanics, Bethel, Conn, USA, 1995.

[35] B. T. Kelly, A newly proposed method for detection, location, and identification of damage in prestressed adjacent box-beam bridges [M.S. thesis], Ohio University, Columbus, Ohio, USA, 2012.

[36] E. Steinberg, R. Miller, D. Nims, and S. Sargand, "Structural evaluation of LIC-310-0396 and FAY-35-17-6.82 box beams with advanced strand deterioration," FHWA Report FHWA/OH2011/16, 2011. 

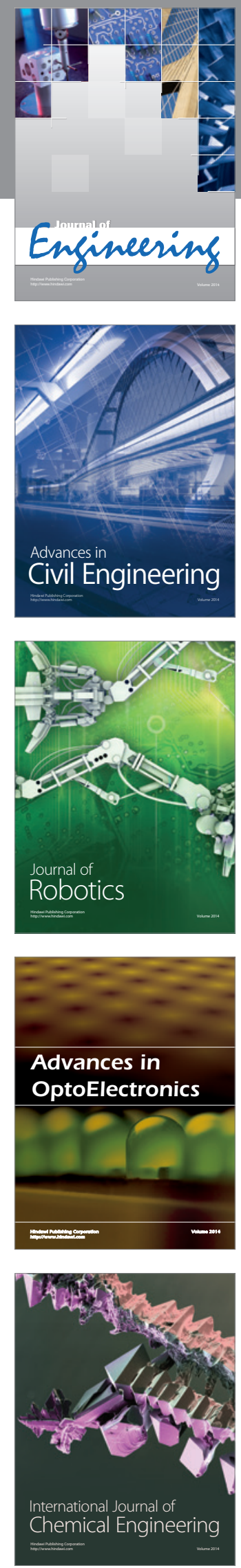

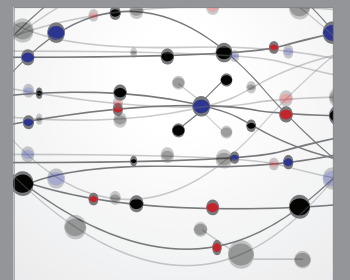

The Scientific World Journal
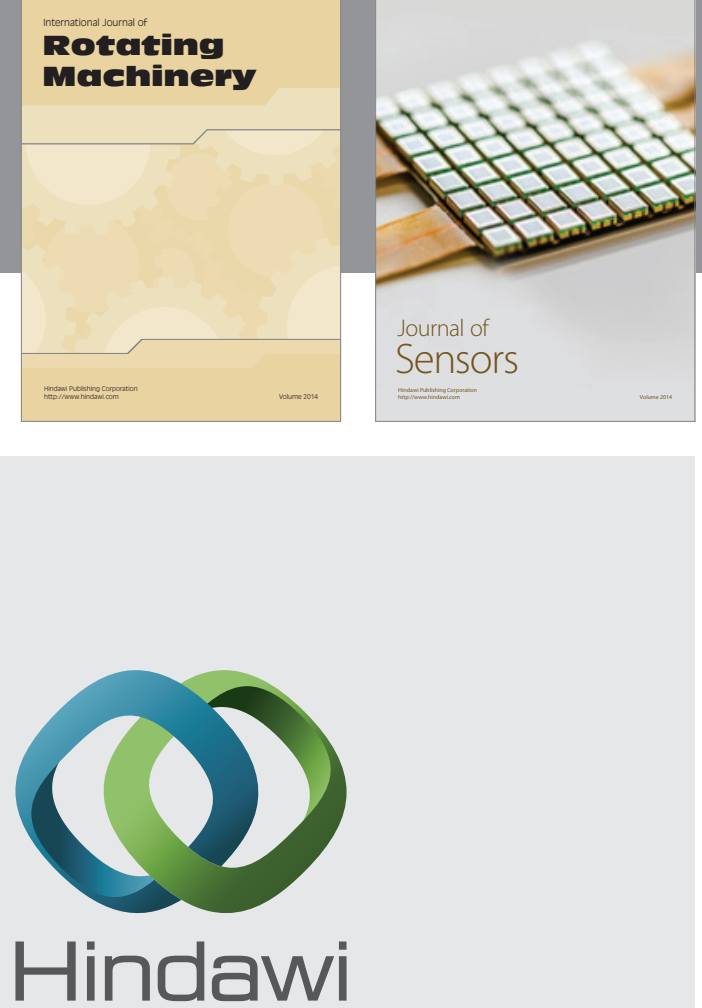

Submit your manuscripts at http://www.hindawi.com
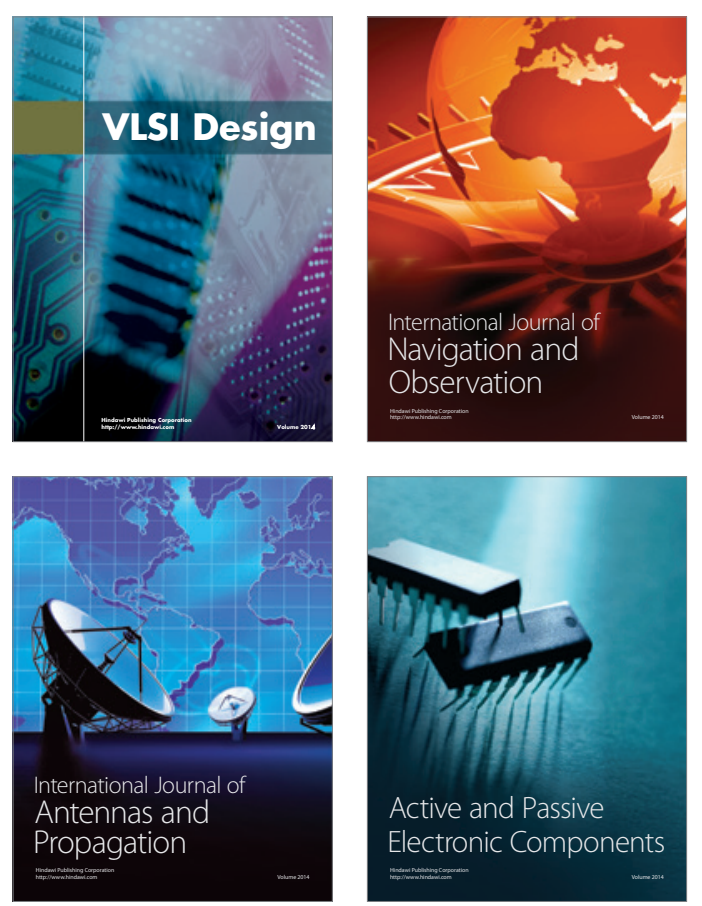
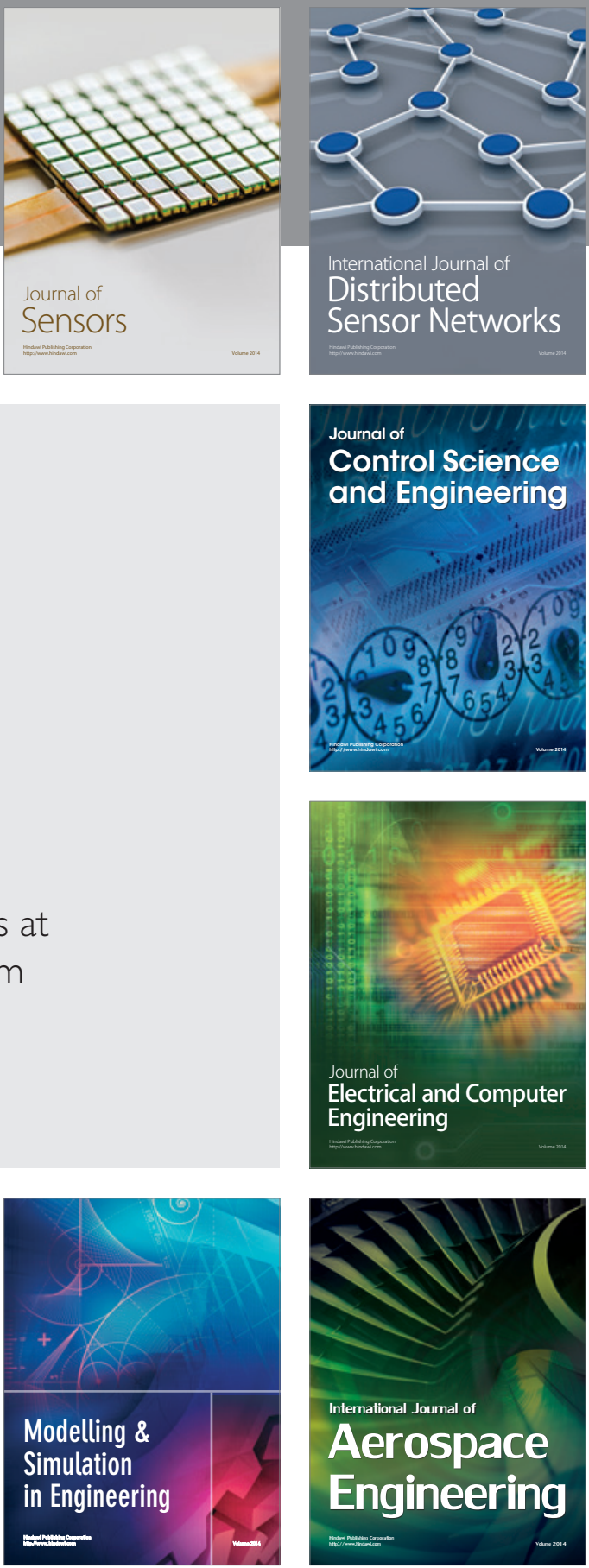

Journal of

Control Science

and Engineering
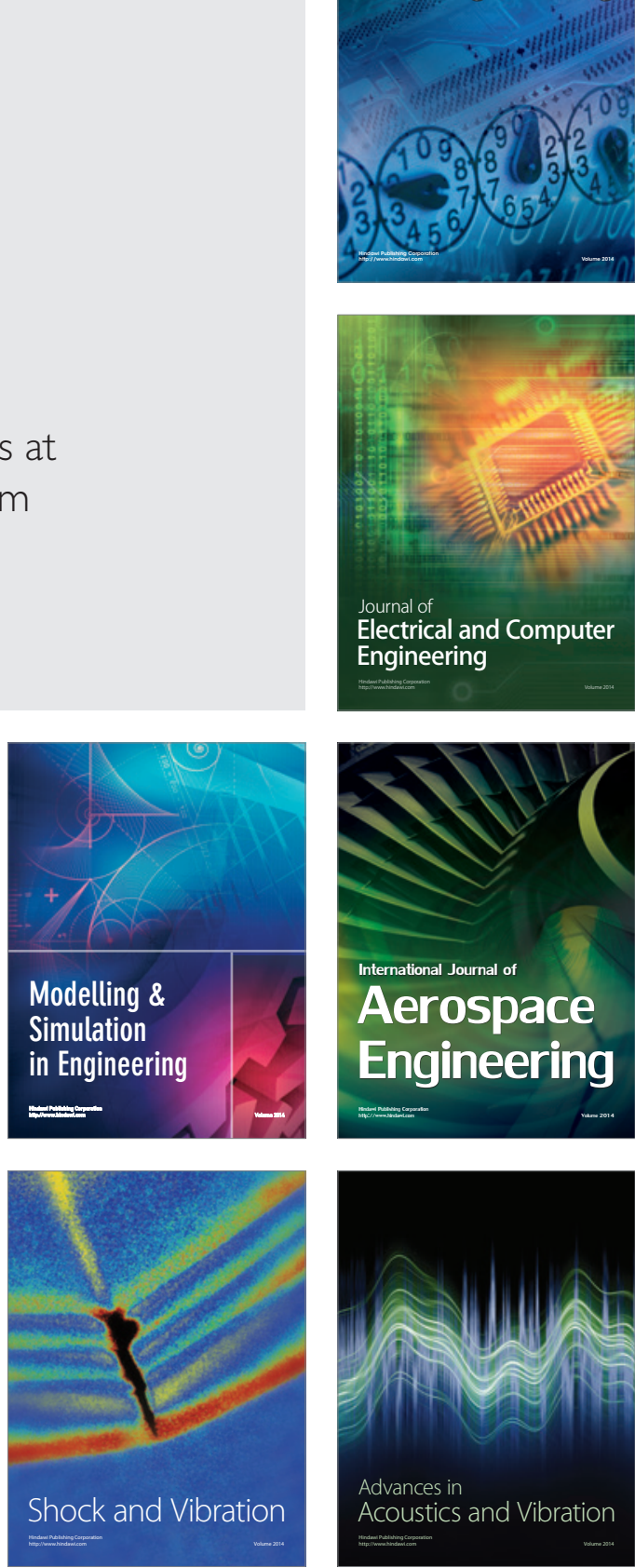